\title{
Poly (ADP-ribose) induces $\alpha$-synuclein aggregation in neuronal-like cells and interacts with phosphorylated $\alpha$-synuclein in post mortem PD samples
}

Laura N. Puentes ${ }^{1}$, Zsofia Lengyel-Zhand ${ }^{2}$, Ji Youn Lee ${ }^{2}$, Chia-Ju Hsieh ${ }^{2}$, Mark E. Schneider

Jr. $^{2}$, Kimberly J. Edwards ${ }^{1}$, Kelvin C. Luk ${ }^{3}$, Virginia M.-Y. Lee ${ }^{3}$, John Q. Trojanowski ${ }^{3}$, Robert H. $\operatorname{Mach}^{2 *}$

${ }^{1}$ Department of Systems Pharmacology and Translational Therapeutics, University of Pennsylvania Perelman School of Medicine, Philadelphia, PA, 19104, USA.

${ }^{2}$ Department of Radiology, University of Pennsylvania Perelman School of Medicine, Philadelphia, PA, 19104, USA.

${ }^{3}$ Department of Pathology and Laboratory Medicine, Institute on Aging and Center for Neurodegenerative Disease Research, University of Pennsylvania Perelman School of Medicine, Philadelphia, PA 19104, USA.

*Corresponding author: Email: rmach@pennmedicine.upenn.edu 


\begin{abstract}
Background

Poly (ADP-ribose) (PAR) is a negatively charged polymer that is biosynthesized by Poly (ADPribose) Polymerase-1 (PARP-1) and regulates various cellular processes. Alpha-synuclein ( $\alpha$ Syn) is an intrinsically disordered protein (IDP) that has been directly implicated with driving the onset and progression of Parkinson's disease (PD). The mechanisms by which $\alpha$ Syn elicits its neurotoxic effects remain unclear. Recent findings indicate that one of the key processes driving PD pathology are oligomeric species of $\alpha$ Syn. Furthermore, it is well established that the main components of Lewy bodies (LBs) and Lewy neurites (LNs) in PD patients are aggregated hyperphosphorylated (S129) forms of $\alpha$ Syn (paSyn).
\end{abstract}

\title{
Methods
}

We used biochemical and immunofluorescence-based assays to explore if PARP-1 enzymatic product (PAR) drives the conversion of monomeric aSyn into aggregated assemblies. We performed quantitative measurements using in situ proximity ligation assays (PLA) on a transgenic murine model of $\alpha$-synucleinopathy (M83-SNCA*A53T) and post-mortem PD/PDD patient samples to characterize PAR-paSyn interactions. Additionally, we used bioinformatic approaches and site-directed mutagenesis to identify PAR-binding regions on fibrillar $\alpha$ Syn.

\section{Results}

Our studies show that elevated intracellular levels of PAR promote the transition of $\alpha$ Syn into higher molecular weight forms. We report that PAR-paSyn interactions are predominant in pathological states. Moreover, we confirm that the interactions between PAR and $\alpha$ Syn involve electrostatic forces between negatively charged PAR and lysine residues on the N-terminal region of $\alpha$ Syn.

\section{Conclusions}

PAR plays a critical role in the early stages of monomeric $\alpha$ Syn aggregation, thereby attributing to PD pathogenesis. Based on our results, we report that PAR seeds monomeric $\alpha$ Syn aggregation and directly interacts with phosphorylated $\alpha$ Syn in conditions that are pathologically relevant to $\mathrm{PD}$. 


\section{Introduction}

A characteristic feature in the pathogenesis of PD involves the accumulation of $\alpha$ Syn protein within the cytoplasm of brain cells ${ }^{1,2}$ - an event that underlies the molecular basis of PD pathology $\mathrm{y}^{3,4}$. While the exact mechanisms associated with PD progression are unknown, it is well understood that the intracellular aggregation of $\alpha$ Syn is directly linked to the neurodegeneration found in $\mathrm{PD}^{1} . \alpha \mathrm{Syn}$ is a protein that primarily exists as a natively unfolded soluble monomer ${ }^{5}$. In neurons, $\alpha$ Syn is believed to function in a variety of synaptic processes, including vesicle trafficking and recycling ${ }^{6-8}$. Depending on the environment, $\alpha$ Syn can undergo a variety of dynamic conformational changes, which include the formation of $\alpha$-helix-rich tetramers $^{9}$, partially folded $\alpha$-helical forms (due to interactions with biological membranes), transitioning into oligomeric species, and producing toxic fibrils that are insoluble and resistant to protease activity ${ }^{10}$. The resulting effect of the latter is a loss in the original protein function and damage in the affected neurons ${ }^{11}$. In PD, $\alpha$ Syn accumulates into higher-order aggregates known as Lewy bodies (LBs) and Lewy neurites (LNs) ${ }^{12}$. The processes by which native $\alpha$ Syn transitions from a monomeric state to a pathogenic aggregate form are unknown. As such, identifying the underlying factors that drive abnormal $\alpha$ Syn assembly are vital to understand the pathogenesis of PD.

Aberrant protein aggregation has been linked to mitochondrial dysfunction and excessive production of reactive oxygen and nitrogen species (ROS/NS) ${ }^{13,14}$. In the last decade, extensive research has been done exploring the role of nuclear protein PARP-1 in promoting neurodegeneration ${ }^{15,16}$. Studies have shown that PARP-1 hyperactivation depletes NAD+, induces an accumulation of PAR, and triggers mitochondrial damage in $\mathrm{AD}^{17}, \mathrm{HD}^{18}, \mathrm{ALS}^{19}$, 
ischemic brains ${ }^{20}$, and $\mathrm{PD}^{16}$. PAR is primarily synthesized by PARP-1 from NAD+ in the nucleus of cells ${ }^{21}$; it regulates cellular processes such as modulating protein localization through covalent (aspartic, glutamic or lysine residues) and noncovalent interactions via PAR-binding motifs (PBMs) on target proteins ${ }^{22}$. Several lines of evidence show that increased levels of intracellular PAR promote liquid demixing and irreversible aggregation of $\operatorname{IDPs}^{23}$. Moreover, PAR and PARylated proteins have been shown to interact directly with pathogenic protein states, such as, $\mathrm{A} \beta^{24}, \mathrm{TDP} 43^{25}$, and hnRNP-A $1^{26}$. Thereby, affecting the aggregation kinetics of these proteins, potentiating toxicity, and promoting cell-to-cell transmission. As such, it has been suggested that the association of PAR and protein aggregates may serve as a feed-forward mechanism that amplifies neurotoxicity and drives neurodegeneration ${ }^{27}$.

A seminal study by Kam and colleagues ${ }^{28}$ revealed that $\alpha$ Syn preformed fibrils (PFF) increase intracellular oxidant levels which result in DNA damage and activation of PARP-1 hyperactivation of PARP-1 leads to the intraneuronal accumulation of PAR and cell death via Parthanatos $^{28}$. It was also reported that PAR binds $\alpha$ Syn PFF resulting in a more stable PFF that displays faster fibrillization kinetics and higher neurotoxicity. Although this paper presented strong experimental evidence showing an interaction between PAR and $\alpha$-synuclein, several unanswered questions remained. Therefore, we felt compelled to fill this scientific gap by asking if we could establish a link between the prevalence of $\alpha$-synuclein-PAR interactions and neuropathology.

To answer these research questions, we employed the use of a human neuroblastoma line overexpressing wild type $\alpha$ Syn wildtype (SH-SY5Y-aSyn) to gather physiologically-relevant information on the role of PAR in $\alpha$ Syn aggregation. We performed in situ proximity ligation 
assays (PLA) to gain respective insight into the pathophysiological significance of PAR- $\alpha$ Syn interactions. We utilized site-directed mutagenesis, immunodot blots, and molecular docking studies to elucidate the nature of these interactions. Altogether, we show that PAR promotes the pathogenic assembly of monomeric $\alpha$ Syn and that PAR-phosphorylated $\alpha$ Syn (paSyn) interactions are predominantly observed in PD-relevant transgenic murine models of $\alpha$ Syn pathology and post-mortem PD/PDD patient samples.

This study provides direct insight into an early trigger of $\alpha$ Syn aggregation. Consistent with previous findings ${ }^{28}$, our results call attention to the role of PARP-1 activity (and PAR polymer) in driving PD neurodegeneration and reinforce the notion that small-molecule inhibitors of PARP-1 hold neuroprotective potential, especially in patients who are at high-risk of developing PD (i.e. patients with autosomal dominant mutations on $\alpha$ Syn).

\section{Results}

\section{PAR polymer induces $\alpha$ Syn oligomerization}

Kam et al., ${ }^{28}$ report that treatment with $N$-methyl- $N$ '-nitro- $N$-nitrosoguanidine (MNNG) - a potent pharmacological PARP activator - promotes aSyn aggregation in SH-SY5Y- $\alpha$ Syn and SH-SY5Y-A53T- $\alpha$ Syn human neuroblastoma cells. Moreover, they report that exogenous administration of PAR induces $\alpha$ Syn aggregation in SH-SY5Y WT and SH-SY5Y PARP-1 KO cells $^{28}$. In our study, we set out to expand on these findings and evaluate whether PAR polymer promotes the transition of natively unstructured $\alpha$ Syn into a disease-associated aggregate state (Fig. 1a). 
Commonly used pharmacological agents that induce PARP-1 hyperactivation also trigger significant genotoxic stress ${ }^{29-31}$. Therefore, to characterize the role of PAR in seeding $\alpha$ Syn aggregation, we employed the use of a protein transduction system, BioPORTER, to deliver a physiologically relevant dose of PAR polymer (50 nM) into SH-SY5Y- $\alpha$ Syn cells (Fig. 1b). The rationale for the use of BioPORTER - instead of a genotoxic agent like $\mathrm{MNNG}^{29}$ - was to develop a neuronal-like cell model that recapitulated the effects of PARP-1 hyperactivation (i.e. elevated PAR) in a genomically stable setting. To determine if PAR itself affects cell viability, we performed cytotoxicity assays on SH-SY5Y-aSyn cells. Results from these assays showed that PAR administration did not lead to significant cell death (Extended Data Fig. 1a).

To assess if PAR increases intracellular superoxide levels, we performed live cell imaging $48 \mathrm{~h}$ post PAR/BioPORTER delivery in transiently transfected Hela cells that were overexpressing an EGFP- $\alpha$ Syn-A53T fusion protein (Extended Data Fig. 1b). Superoxide levels were detected with MitoSOXTM Red (a superoxide indicator reagent) and imaged via fluorescence microscopy. Results from these studies showed that PAR treatment increased intracellular superoxide levels in Hela cells when compared to BioPORTER alone (Extended Data Fig. 1b).

To obtain a quantitative measure of aSyn oligomerization, we used an enzyme-linked immunosorbent assay (ELISA), specific for human $\alpha$ Syn oligomers, to evaluate if elevated levels of PAR in SH-SY5Y- $\alpha$ Syn cells promote the conversion of monomeric $\alpha$ Syn into oligomeric forms. Results from the ELISA (Fig. 1c) indicate that cell lysates from PAR treated samples had higher $\alpha$ Syn oligomeric signal compared to vehicle controls.

To further validate our ELISA data, we set up an immunodot blot experiment, whereby, cell lysates were spotted onto a membrane and assayed for the presence of amyloid oligomers using 
an A11 antibody that has been previously validated by our group ${ }^{32}$ and others ${ }^{33,34}$ and is specific for prefibrillar oligomers ranging in size from $40-75 \mathrm{kDa}^{34}$ (Fig. 1d, Supplementary Table 1). To investigate if the increase in A11 oligomer signal (48 h post-treatment) was PAR-specific, we used a small molecule PARG inhibitor (PDD 00017273) $)^{35}$ to increase endogenous PAR levels. PARG is an enzyme that regulates intracellular PAR levels via its exo- and endoglycosidase activities $^{36}$. Thus, to reduce PAR catabolism, we pre-treated SH-SY5Y- $\alpha$ Syn cells with $1 \mu \mathrm{M}$ PARG inhibitor PDD 00017273, 1 h prior to BioPORTER delivery of $50 \mathrm{nM}$ PAR. Additionally - and in parallel - we used BioPORTER to deliver $50 \mathrm{nM}$ of adenosine diphosphate (hydroxymethyl)pyrrolidinediol (ADP-HDP) ${ }^{37}$ into SH-SY5Y- $\alpha$ Syn cells to assess if the stable NH-analog of ADP-ribose was sufficient to induce intracellular $\alpha$ Syn aggregation (Fig. 1d). Results from the A11 immunodot blot assay showed higher oligomeric signal in the PAR and PAR + PARGi samples, compared to vehicle control and ADP-HDP treated samples (Fig. 1d); thus, corroborating our $\alpha$ Syn oligomer ELISA data (Fig. 1c).

Since misfolded $\alpha$ Syn seeds and drives pathology in cell and animal models of $\mathrm{PD}^{38,39}$, we performed biochemical analysis to test for the presence of higher molecular weight forms of $\alpha$ Syn. For these experiments, we used a conformation-selective $\alpha$ Syn antibody (Syn303) which recognizes total and misfolded synuclein ${ }^{40,41}$ (Fig. 1e, Supplementary Table 1). Results from these experiments showed an increase in band intensity for a higher molecular weight form of aSyn ( $42 \mathrm{kDa})$ in the PAR + PARGi treated samples $48 \mathrm{~h}$ post treatment (Fig. 1e). Moreover, these results confirm that continuously elevated levels of PAR promote the formation of higher molecular weight $\alpha$ Syn aggregates. 
Recent evidence suggests that $\alpha \mathrm{Syn}$ is a DNA binding protein that interacts with $\gamma \mathrm{H} 2 \mathrm{AX}$ and PAR on sites of DNA damage ${ }^{42}$. Therefore, we sought to determine if elevated levels of PAR can lead to DNA damage. We immunoblotted for $\gamma \mathrm{H} 2 \mathrm{AX}$ and observed an increase in $\gamma \mathrm{H} 2 \mathrm{AX}$ band intensity in the PAR and PAR + PARGi treated samples when compared to vehicle control and ADP-HDP treated samples (Extended Data Fig.1c). This data suggests that PAR alone can trigger DNA damage. Since PARP-1 activity accounts for the majority of PAR in the cell ${ }^{43}$, it stands to reason that PARP-1 hyperactivity (i.e. elevated PAR formation) promotes further DNA

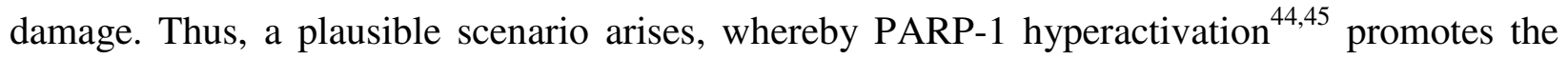
interactions of PAR and $\alpha$ Syn at sites of DNA damage.

In summary, our results suggest that elevated PAR levels, while not directly toxic, can lead to oxidative stress and DNA damage. Furthermore, we show that PAR itself promotes the transition of monomeric $\alpha$ Syn into higher molecular weight (i.e. oligomeric) forms.

PAR colocalizes with phosphorylated (S129) aSyn Aggregates

In physiological settings, approximately $4 \%$ of soluble $\alpha$ Syn is phosphorylated at amino acid residue S129 (paSyn $)^{46,47}$. Correlations have been established between paSyn status and pathological conditions ${ }^{48,49}$. In PD patients, $\alpha$ Syn found within inclusions (LBs, LNs) tend to be hyperphosphoryated at S129. In LBs, it is estimated that up to $90 \%$ of $\alpha$ Syn is phosphorylated at $\mathrm{S} 129^{47}$. paSyn is observed in other synucleinopathies (neurodegenerative diseases characterized by abnormal accumulation of $\alpha$ Syn aggregates) including dementia with LBs (DLB) ${ }^{50}$ and multiple system atrophy (MSA) ${ }^{51}$. In addition, increased levels of paSyn has been reported in PD-like transgenic murine models ${ }^{6}$. 
Here, we asked whether PAR interacts directly with paSyn aggregates. To address this question, we used our previously described cell model (Fig. 1b) which mimics PARP-1 hyperactivation and introduced either: PAR, ADP-HDP or BioPORTER alone (vehicle control). After a $48 \mathrm{~h}$ incubation, the cells were immunostained with an antibody directed towards paSyn. Using fluorescence microscopy, we identified paSyn inclusions ( $1 \mu \mathrm{m}$ length) in the cytoplasm of PAR treated cells (Fig. 2a,b). We also noted that PAR signal overlapped with $\sim 60 \%$ of these cellular paSyn inclusions when co-immunostaining with a PAR-specific antibody (Fig. 2c); antibody information can be found in Supplementary Table 1.

Our studies show that PAR-mediated $\alpha$ Syn aggregation results in the appearance of cytosolic paSyn inclusions (Fig. 2a,c) by 48 h. By contrast, these paSyn inclusions were not observed in the ADP-HDP treated or vehicle control samples (Fig. 2a,b). In addition, quantification of coimmunostained samples using image processing software, indicate that while over half of the paSyn inclusions were colocalized with PAR signal (Fig. 2d,f), the majority of PAR signal was not colocalized with paSyn (Fig. 2d). The latter was not surprising given the diverse roles that PAR plays in the cell ${ }^{52,53}$.

\section{PAR directly interacts with phosphorylated (S129) aSyn}

To directly measure the interactions between PAR and paSyn in our cell model, we used antibodies against $\mathrm{PAR}^{54}$ and $\operatorname{paSyn}^{55}$ (Supplementary Table 1) and employed the use of an insitu PLA ${ }^{56}$. The utilization of PLA allowed us to record the prevalence of PAR-paSyn interactions with greater sensitivity and specificity when compared to traditional immunoassays.

A time course experiment on our cell model, showed a clear time-dependent difference in PLA signal by $48 \mathrm{~h}$ between the PAR and PAR + PARGi treated samples in comparison to the ADP- 
HDP treated and vehicle control samples (Fig. 3a,b); earlier time points (i.e. $4 \mathrm{~h}$ and $24 \mathrm{~h}$ ) also showed higher PLA signal for the PAR and PAR + PARGi treated samples (Extended Data Fig. 1d,e). Our data showed an initial increase in PLA signal for ADP-HDP treated samples at $4 \mathrm{~h}$ (Extended Data Fig. 1d), however, after $24 \mathrm{~h}$ the signal fell below detection for this treatment condition (Extended Data Fig. 1e). A potential reason for the drop in PLA signal after $24 \mathrm{~h}-$ for the ADP-HDP treated samples - could be attributed to the degradation of ADP-HDP by phosphodiesterases in the cell ${ }^{57}$.

In accordance with our previous findings, not only does PAR polymer promote the oligomerization of $\alpha$ Syn, it also directly interacts with paSyn inclusions. The evidence from our cell model, suggests that PAR has a dual role in the aggregation pathway of $\alpha$ Syn, whereby it functions as a molecular seed that nucleates monomeric aSyn (resulting in higher molecular weight forms of $\alpha$ Syn) and perhaps stabilizes paSyn inclusions, as evidenced by our PAR-p $\alpha$ Syn colocalization and PLA studies.

PAR and paSyn interactions are prevalent in PD-like transgenic mouse models of $\alpha$ synucleinopathies

In order to assess if PAR-paSyn interactions are present in $\alpha$ Syn pathology, we used a transgenic (Tg) murine model of $\alpha$-synucleinopathy (M83 SCNA*A53T) that develops a PD-like phenotype with age ${ }^{58}$. The Tg murine line (M83) used in this study overexpresses a form of human $\alpha$ Syn that harbors a point mutation at amino acid residue 53 (A53T); this point mutation has been directly implicated in familial early onset $\mathrm{PD}^{59}$. Information on the animals used in this study can be found in Supplementary Table 2. 
The Tg mice were separated into two groups: M83 Tg young (less than $12 \mathrm{mo}$ ) and M83 Tg aged (12 mo or older). To control for age-related effects, we also used a non-transgenic murine line (B6C3F1/J) in our studies (Supplementary Table 2). Following euthanasia, murine brains were dissected and hemisected in the sagittal plane. Immunostaining for endogenous PAR was carried out to assess PARP-1 activity. PAR intensity (particularly in the cerebral cortex) increased with age in both M83 Tg and non-Tg mice (Extended Data Fig. 2a). Similarly, we immunostained M83 Tg and non-Tg mice to assess whole brain paSyn expression (Extended Data Fig. 2b). Based on these experiments, we observed a remarkable increase in paSyn expression in an M83 Tg aged (17 mo) sample - with maximum signal output measured in the brainstem and cerebral cortex regions (Extended Data Fig. 2b). In addition, we show that PAR and paSyn staining significantly increased with age in the M83 Tg brain samples, thus suggesting an association between increased PAR and paSyn expression and disease phenotype.

To measure the prevalence of PAR-paSyn interactions, we performed in situ PLA on frozen brain sections from all three animal groups: M83 Tg young, M83 $\mathrm{Tg}$ aged and non-Tg (B6C3F1/J). To limit non-specific PLA signal, we included technical controls, whereby adjacent brain tissue sections were incubated without primary antibodies (data not shown), subsequent imaging parameters (i.e. exposure time, depth of field) were then adjusted in order to acquire detectable signal above background. To ensure consistency between experimental models, we used the same primary antibodies (anti-PAR and anti-paSyn, Supplementary Table 1) for our cell and animal brain tissue PLA.

Results from our studies revealed that PLA signal for PAR-paSyn was strongest in M83 Tg vs. non-Tg mice (Fig. 3c,d). Analogously, M83 Tg aged vs. M83 Tg young mice differed 
significantly in PLA signal (Fig. 3c,d) - with the strongest signal differential detected in the brainstem region of the M83 Tg aged group (Fig. 3e,f). Similarly, increased PLA signal was also observed in an M83 Tg aged mouse (18 mo) when using primary antibodies against PAR and total $\alpha$ Syn (anti-PAN- $\alpha$ Syn) (Extended Data Fig. 2c), thus confirming that PAR interacts with both phosphorylated and non-phosphorylated $\alpha$ Syn. In addition, we noted that M83 Tg brain tissue samples with the highest paSyn expression also had the greatest PLA signal output, suggesting that paSyn-PAR PLA signal is directly tied to the amount of pathology (i.e. paSyn expression) present in a given sample.

Overall, our studies revealed that PLA signal was highest in anatomical brain regions most commonly associated with aSyn pathology in the M83 Tg aged group (38) (Fig. 3e,f); these findings are in accordance with our observations from the SH-SY5Y- $\alpha$ Syn cell model, which show that PAR-paSyn interactions are prevalent in pathogenic states involving $\alpha$ Syn aggregation and PARP hyperactivity i.e. elevated PAR levels.

PAR-paSyn interactions are observed in post mortem brain tissue from PD/PDD patients

To determine the clinical relevance of PAR-paSyn interactions in PD, we performed immunoassays and PLA on human post mortem striatum and midfrontal gyrus brain regions derived from PD and PDD (Parkinson's Disease Dementia) patients, as well as, non-PD controls. Patient information can be found in Supplementary Table 3.

Results from these studies, revealed heterogeneity in paSyn (Extended Data Fig. 3a) and PAR (Extended Data Fig. 3b) immunostaining for all patient samples. Overall, PD/PDD patient samples exhibited increased paSyn expression (Fig. 4a,b), while PAR expression in the PD/PDD 
patient samples was more heterogeneous (Extended Data Fig. 3b). Interestingly, we observed higher signal overlap (i.e. colocalization) between PAR and paSyn staining in the PD/PDD patient samples, as determined by Manders' overlap coefficient. (Fig. 4d). Cumulatively, the PD/PDD patient group had higher paSyn (Fig. 4b), PAR (Fig. 4c), and PLA (Fig. 5 a-c) signal, when compared to the non-PD controls. Moreover, PLA signal output for the PD/PDD patient group was in accordance with our PAR- paSyn colocalization analysis.

To further validate our PD/PDD PLA results, we performed paSyn-PAR PLA on cerebellum tissue samples from patients diagnosed with multiple system atrophy (MSA) - another main type of $\alpha$-synucleinopathy - along with healthy cerebellum tissue controls (Extended Data Fig. 3c). We observed PLA staining patterns that closely matched paSyn pathology in MSA (Extended Data Fig. 3 c,d). As a result, we were able to validate PLA signal in two different $\alpha$ synucleinopathies.

In summary, even though we observed heterogeneous expression for paSyn and PAR staining in the patient tissue samples, based on our analysis, we can deduce that PLA signal is higher in the PD/PDD patient group. The data obtained from these experiments, to our knowledge, is the first direct evidence showing pathologically relevant PAR-paSyn associations on human post mortem brain tissue samples from PD/PDD and MSA patient groups. Further studies are merited in order to better understand this association as it would be of medical significance to evaluate if PARbound paSyn has potential as an early PD/PDD biomarker - such a finding could have wide ranging implications for the development of disease modifying therapies for patients harboring familial PD genetic variants (i.e. A30P, E46K, and A53T). 
PAR binds $\alpha$ Syn via electrostatic interactions involving lysine residues

A previous study ${ }^{28}$ showed that PAR binds $\alpha$ Syn via non-covalent interactions on the N-terminal region of $\alpha$ Syn - thus, suggesting that the interactions between PAR and $\alpha$ Syn are electrostatic in nature. In order to identify the amino acid residues involved in $\alpha$ Syn-PAR binding, a protein alignment tool (NPS@PATTINPROT search) was used to align the native $\alpha$ Syn protein sequence to two published PAR binding motifs $(\mathrm{PBM})^{22,60}$. We identified two sites on $\alpha$ Syn as potential PAR-binding sites (Fig. 6a): a site between amino acids residues 43-54 and another site between amino acid residues 48-58.

To better characterize $\alpha$ Syn-PAR interactions, we substituted positively charged lysine residues at the two PAR-binding sites predicted by the NPS@PATTINPROT tool (Fig. 6a). Using sitedirected mutagenesis, we generated three mutants of $\alpha$ Syn with compromised PAR-binding sites by replacing lysine residues with neutral alanine residues (Fig. 6a). Two of the $\alpha$ Syn mutants had a single point mutation at amino acid residues K43 \& K58 respectively, while the third mutant had two point mutations at positions K43 and K45 (Fig. 6a,b). Fibrillization of the $\alpha$ Syn mutants was followed using Thioflavin $\mathrm{T}$ (ThT) (Extended Data Fig. 4a) and transmission electron microscopy (TEM) (Fig. 6b). The introduced mutations decreased the rate of aSyn fibril formation by increasing the lag-phase relative to the wild type (WT) protein (Extended Data Fig. 4a). Despite the initial slow aggregation kinetics, all mutants were fully fibrillated within $72 \mathrm{~h}$ as shown by ThT (Extended Data Fig. 4a) and TEM (Fig. 6b). We observed kinetic variability in mutant-seeded formation of $\alpha$ Syn fibrils from the single point mutant K43 and the double point mutant K43 and K45, as determined by ThT (Extended Data Fig. 4b). Cytotoxicity assays on IMR-5 neuroblastoma cells revealed that the $\alpha$ Syn mutant fibrils were less toxic compared to 
PAR-bound $\alpha$ Syn WT fibrils (Extended Data Fig. 4c), these results are in accordance with previous observations ${ }^{28}$ which show that PAR-bound fibrils display higher neurotoxicity. Thus, reinforcing the notion that PAR enhances the toxicity of $\alpha$ Syn aggregates.

To test if PAR binding was affected in the generated $\alpha$ Syn mutant fibrils, we performed PARbinding immunodot blot (Fig. 6c). WT and mutant $\alpha$ Syn fibrils were spotted onto a membrane along with a PAR-binding protein, histone H4 (positive control) and BSA (negative control). Incubation with PAR polymer, followed by immunoblotting with a PAR-specific antibody $(10 \mathrm{H})$, revealed that both histone $\mathrm{H} 4$ and $\alpha$ Syn WT fibril bound to PAR. Interestingly, we observed a decrease in PAR binding for all three mutants when compared to $\alpha$ Syn WT fibril (Fig. 6c).

To assess if the decrease in PAR binding on the alanine mutant fibrils was a direct result of substituting positively-charged lysine residues -and not just due to the introduction of a point mutation, we performed an additional PAR-binding immunodot blot with aSyn A53T fibril. From this, we observed that PAR binds the aSyn A53T mutant with similar signal intensity compared to $\alpha$ Syn WT fibril (Extended Data Fig. 3d). Based on these results, we confirm that PAR binding to $\alpha$ Syn is primarily mediated by electrostatic interactions at positions $43-58$ of the N-terminal region. Our data also indicates that PAR binds a known familial point mutation of $\alpha$ Syn (A53T) (Extended Data Fig. 4d). The latter has direct relevance in patients who harbor the A53T variant of $\alpha$ Syn - as this variant has been shown to be aggregation prone and has been directly linked to autosomal dominant early onset PD.

PAR, MSA, and beyond 
The cryo-EM structure of Sarkosyl-insoluble $\alpha$ Syn filaments isolated from five MSA cases was recently reported $^{61}$. Two different filament types were reported, type I and type II. Both filament types consist of two different protofilaments having an extended N-terminus and compact Cterminal body. In addition, the interface between the two different protofilaments consist of a non-proteinaceous density in the region of K43 and K45 in one protofilament, and K58 of the other protofilament. Since replacement of these lysine residues with an alanine residue diminished PAR binding (Fig. 6c) and given that PAR and paSyn interact in both PD/PDD (Fig. 5a,c) and MSA brain tissue (Extended Data Fig. 3c), we propose that this non-proteinaceous density is likely to be PAR.

To evaluate this hypothesis, a series of computational chemistry studies (Fig. 6d,e) were conducted in order to probe the interaction of a PAR-dimer (Fig. 6d) with the cryo-EM structure of $\alpha$ Syn, specifically the type I filament ${ }^{61}$. From this, we found a very strong fit of the PARdimer in the space occupied by this non-proteinaceous density - with strong ionic interactions between these lysine residues and the diphosphate moiety of the PAR-dimer and hydrogen bond interactions between tyrosine-39 and histidine-50 with the adenine group and ribose groups (Fig. 6e). Altogether, our results are consistent with PAR being the non-proteinaceous density in the $\alpha$ Syn filaments reported in MSA.

\section{Discussion}

PAR is a highly branched polymer that has been best characterized as a recruiter of DNA repair factors during single-strand DNA break repair. However, in recent years the role of PAR outside of the nucleus has become clearer and the role of this polymer in neurodegeneration stands as a promising avenue for better understanding the molecular basis of neurotoxicity that gives way to 
neurodegeneration. Specifically, looking at PAR in PD points to a potential role for this polymer as a nucleating driver of $\alpha$ Syn aggregation. Understanding this interaction and relating it to disease progression points to PAR and presumably PAR- $\alpha$ Syn interactions, specifically, as potential early biomarkers for disease. Such a finding, holds wide implications for early prognosis and further presses on the need to develop robust PARP inhibitors that reduce PARP-1 activity without eliciting toxicity in cells. In addition, the significant interactions between PARpaSyn observed in post mortem PD/PDD patient samples suggests that this interaction might be prevalent in disease. Our studies also confirm that PAR and $\alpha$ Syn interact via electrostatic forces involving positively-charged lysine residues on $\alpha$ Syn. Altogether, our observations potentiate the need to further study the association of $\alpha$ Syn-PAR as it pertains to disease and explore the possibility of using this interaction as the basis for developing disease modifying therapies and prognostic tools to track disease progression. Our findings reinforce the notion that PARP-1 hyperactivity (and resulting intracellular PAR accumulation) is a key driver of neurodegeneration. Thus, highlighting the need to evaluate if early interventions with PARP-1 inhibitors can translate into preventative measures for individuals who are at higher risk of developing PD.

\section{Study Design}

The objectives of this study were to evaluate the role of PAR in driving monomeric $\alpha$ Syn aggregation, elucidate PAR binding to paSyn in pathology-associated cell, murine, and human post mortem brain samples, and identify the amino acid residues involved in $\alpha$ Syn fibril-PAR binding. These controlled laboratory experiments involved the use of immunostaining, PLA, molecular biology, and computational chemistry techniques. 
Immunostaining and PLA results were analyzed using CellProfiler $3.0^{62}$ software, whereby, specialized pipelines were implemented to identify and count PAR and paSyn staining (Cell/particle counting pipeline) or PLA dot signal (modified Speckle Counting pipeline; whereby PLA dots were identified within cells' cytoplasm). These measurements were then normalized to DAPI count to obtain an output measure of total target signal/total cell count per field of view $(10-15)$ for each sample.

For animal studies, sample size for each age group was $n=3$. Age groups were determined via PAR immunostaining, whereby, mice that were 12 mo of age and older displayed higher PAR intensity. The oldest mice in our study were between $17 \mathrm{mo}$ and $18 \mathrm{mo}$ of age, therefore, we defined 17 mo as the end point for our murine data collection. Mice that were older than 12 mo were included in the "aged" group, whereas, mice that were younger than 12 mo were included in the "young" group. Similarly, we used littermate controls for the "aged" group to account for age-related effects. Information on the strain, sex, and age of the mice used in this study can be found in Supplementary Table 2. For studies on post mortem tissue samples, PD/PDD cases were characterized by PD type pathology (Supplementary Table 3).

\section{Materials and Methods}

\section{PAR polymer}

Purified PAR polymer chains (commercially obtained from TREVIGEN) were synthesized from PARP-1 in the presence of NAD ${ }^{+}$, cleaved and subsequently purified. PAR chain lengths ranged in size from 2-300 ADP-ribose subunits, with a final concentration of $10 \mu \mathrm{M}$.

\section{Cell Culture}


SH-SY5Y- $\alpha$ Syn cells were transfected using Lipofectamine 2000 (Invitrogen) with pcDNA3.1 expression vector following manufacturer's protocol. The expression vector contained the fulllength human wild type $\alpha$ Syn cDNAs, cloned in the polylinker region at the KpnI and ApaI sites. Stable transfected cell lines were selected and maintained in complete medium containing 300 $\mu \mathrm{g} / \mathrm{ml} \mathrm{G418}$ (Invitrogen) ${ }^{63}$. The cells were maintained in DMEM/F12 media with GlutaMAX supplement (Thermofisher scientific, Cat\#10565018), 10\% heat-inactivated fetal calf serum (FBS), 100 units/ml penicillin and $100 \mu \mathrm{g} / \mathrm{ml}$ streptomycin (Pen-Strep), in a humid atmosphere of $5 \% \mathrm{CO}^{2}$ and $95 \% \mathrm{O}^{2}$ at $37^{\circ} \mathrm{C}$.

\section{BioPORTER Experiments}

SH-SY5Y- $\alpha$ Syn cells were seeded at concentrations of 16,000 cells/well in Nunc $®$ Lab-Tek® Chamber Slide ${ }^{\mathrm{TM}}$ system ( 8 wells, $0.8 \mathrm{~cm}^{2} /$ well) (Millipore ${ }^{\circledR}, \mathrm{C} 7182-1 \mathrm{PAK}$ ) for fluorescent microscopy experiments (IF and PLA) or at $2 \times 10^{6}$ in $150 \mathrm{~mm}$ TC treated (ThermoFisher Scientific, Cat\#FB012925) dishes for biochemical assays (Western, ELISA, immunodot) $24 \mathrm{~h}$ before incubation with either PAR + BioPORTER, ADP-HDP + BioPORTER or BioPORTER alone (vehicle control). BioPORTER Protein Delivery Reagent “QuikEase Kit” (Genlantis, Cat\#BP502424) was prepared according to the manufacturer's protocol, briefly described as follows. Either PAR or ADP-HDP were diluted in $100 \mu \mathrm{L}$ PBS to a final concentration of $50 \mathrm{nM}$, the diluted solution was then added to a QuikEase Single-Use Tube containing the dried BioPORTER reagent, mixed by pipetting 3-5 times, incubated at room temperature (RT) for 5 min and gently vortexed (post-incubation) for 3-5 s. Opti-MEM I Reduced Serum Medium (Life Technologies Inc., Cat\#31985062) was used to bring the final volume in each QuikEase SingleUse Tube to $500 \mu \mathrm{L}$. The cells were washed once with Reduced Serum Medium 1 h before 
BioPORTER delivery, then replenished with either $200 \mu \mathrm{L}$ (chamber slide cells) or $6 \mathrm{~mL}(150$ mm dish cells) of Opti-MEM I (ThermoFisher Scientific, Cat\#31985062). BioPORTER medium mix was added at a 1:1 volume ratio in the cells grown in chamber slides and a 1:3 volume ratio in the cells grown in $150 \mathrm{~mm}$ dishes. The cells were subsequently incubated for $4 \mathrm{~h}$ at $37^{\circ} \mathrm{C}$. After $4 \mathrm{~h}$, one volume of $20 \%$ serum-containing medium was added directly to the chamber slides/dishes, $24 \mathrm{~h}$ post-BioPORTER delivery, the medium was aspirated from the chamber slides/dishes and replenished with complete growth medium (DMEM/F12 media with GlutaMAX supplement). $48 \mathrm{~h}$ after BioPORTER delivery, the cells were washed 2X with PBS and processed for downstream experiments.

\section{Cell Viability Assays}

Cells were seeded in black wall clear bottom 96-well plates (Corning®) at concentrations of 1000 cells/well. For PAR toxicity assay, SH-SY5Y cells were treated with three concentrations of PAR ranging from 25 to $100 \mathrm{nM}$ for $48 \mathrm{~h}$. For pre-formed fibril (PFF) toxicity assays, IMR-5 cells were treated with $750 \mathrm{nM}$ PFF for five days. Following treatment incubation, the cells were assayed for viability using the luminescent based assay, CellTiter Glo (Promega Corp.), following manufacturer's protocol. Plates were read on an Enspire multimode plate reader (PerkinElmer, Inc.). Data was normalized to percent survival at each concentration evaluated by dividing the luminescent signal in treated wells by the average of PBS controls. Experiments were repeated three times.

\section{Transfection of Hela cells with EGFP-aSyn-A53T}

Hela cells were transiently transfected using Lipofectamine 3000 (Invitrogen) with a pEGFP-C1 mammalian vector containing full length human A53T variant $\alpha$ Syn with a fusion EGFP tag 
(Addgene, Plasmid \#40823), following the manufacturer's protocol. The transfected cells were maintained in complete medium (DMEM media, 10\% FBS, 1\% Pen-Strep) and used within 2 days of transfection for downstream experiments.

\section{MitoSOXTM Red}

Hela-EGFP- $\alpha$ Syn-A53T cells were seeded at concentrations of 5,000 cells/well in Nunc® LabTek ${ }^{\circledR}$ Chamber Slide ${ }^{\mathrm{TM}}$ system. BioPORTER delivery was used to deliver $50 \mathrm{nM}$ PAR polymer, as described above, BioPORTER alone was used as a vehicle control. $48 \mathrm{~h}$ post-PAR delivery, cells were treated with $75 \mathrm{nM}$ MitoSOXTM Red reagent (ThermoFisher, Cat\#M36008) for 30 min at $37^{\circ} \mathrm{C}$ to detect production of superoxide by mitochondria in Hela-EGFP-aSyn-A53T cells. After incubation, the cells were fixed with ice cold methanol for $15 \mathrm{~min}$ at $4{ }^{\circ} \mathrm{C}$, washed $3 \mathrm{X}$ with PBS and processed for imaging using Zeiss Axio Widefield microscope (20x/0.8).

\section{Animals}

M83-SNCA*A53T mice expressing human A53T variant $\alpha$ Syn were obtained from The Jackson Laboratory, Bar Harbor, ME (JAX stock \#004479). All mice were on B6;C3H genetic background. Animals were housed under controlled temperature and lighting conditions and had free access to food and water. All animal procedures were approved by IACUC and were in accordance with the National Institutes of Health Guide for the Care and Use of Laboratory Animals.

\section{Human Post Mortem Brain aSyn Pathology Analysis}


Human brain samples were obtained from University of Pennsylvania's Center for Neurodegenerative Disease Research Brain Bank and were evaluated with standardized histopathological methods as described ${ }^{64-66}$.

\section{Immunofluorescence (IF) Staining}

$48 \mathrm{~h}$ post-BioPORTER delivery, SH-SY5Y- $\alpha$ Syn cells (seeded on chamber slides at 16,000 cells per well) were fixed on ice with $4 \%$ paraformaldehyde for $8 \mathrm{~min}$. The cells were then washed $3 X$ with PBS and permeabilized with $0.1 \%$ Triton X-100 for $10 \mathrm{~min}$ at RT. After permeabilization, the cells were washed $3 \mathrm{X}$ with PBS-T (PBS with $0.1 \%$ Tween-20) at RT. After the third wash, $200 \mu \mathrm{L}$ of $10 \%$ goat serum (ThermoFisher, Cat\#50062Z) was added to each well for $1 \mathrm{~h}$ at $37^{\circ} \mathrm{C}$ to block non-specific immuno binding. After blocking, the cells were sequentially incubated with primary antibodies (Supplementary Table 1) targeting PAR (10H) and paSyn (ps129) overnight at $4^{\circ} \mathrm{C}$. Following primary antibody incubation, the cells were washed $3 \mathrm{X}$ with PBS-T. After the third wash, the cells were then sequentially incubated with secondary antibodies (Supplementary Table 1) for $1 \mathrm{~h}$ at $37^{\circ} \mathrm{C}$, washed $3 \mathrm{X}$ with PBS-T and stained with DAPI. Coverslips were placed on each slide and the slides were allowed to dry overnight at $4^{\circ} \mathrm{C}$. Images were captured using Zeiss LSM 710 confocal (40x/1.4 Oil) and Zeiss Axio Widefield (20x/0.8) microscopes (Supplementary Table 4).

Human post mortem tissue sections were treated with TrueBlack (TrueBlack® Lipofuscin Autofluorescence Quencher) according to manufacturer's protocol, in order to eliminate lipofuscin autofluorescence before immunostaining.

Following the blocking step with $10 \%$ goat serum, murine tissue sections underwent an additional blocking step with anti-mouse $\operatorname{IgG}$ (Supplementary Table 1 ) for $1 \mathrm{~h}$ at $37^{\circ} \mathrm{C}$ in order to 
reduce nonspecific signal from secondary antibodies directed against PAR antibody (10H), which is a mouse monoclonal primary antibody.

\section{Proximity Ligation Assay (PLA)}

$48 \mathrm{~h}$ post-BioPORTER delivery, chamber slides cells (SH-SY5Y-aSyn cells) were processed with regards to fixation and permeabilization using the IF protocol described in the previous section. In situ PLA was performed according to the manufacturer's protocol, briefly described as follows. Following permeabilization, cells were blocked using Duolink® Blocking Solution for 1 $\mathrm{h}$ at $37^{\circ} \mathrm{C}$. PAR primary antibody (Supplementary Table 1) was diluted in Duolink® Antibody Diluent, added to the cells and incubated overnight at $4^{\circ} \mathrm{C}$. Following overnight incubation with PAR primary antibody, the cells were washed $2 \mathrm{X}$ with Duolink® Wash Buffer A, then incubated with Duolink® PLA Probe (goat anti-mouse $M I N U S$ ) for $1 \mathrm{~h}$ at $37^{\circ} \mathrm{C}$. After incubation with PLA Probe MINUS, the cells were washed 2X with Wash Buffer A, blocked with Duolink® Blocking Solution for $1 \mathrm{~h}$ at $37^{\circ} \mathrm{C}$ and incubated overnight at $4^{\circ} \mathrm{C}$ with primary antibody targeting paSyn (Supplementary Table 1). Following overnight incubation, the cells were washed $2 \mathrm{X}$ with Wash Buffer A and incubated with Duolink® PLA Probe (goat anti-rabbit $P L U S$ ) for $1 \mathrm{~h}$ at $37^{\circ} \mathrm{C}$. Following the sequential addition of primary antibodies and corresponding PLA Probes, the cells were processed with respect to ligation (Duolink® Ligation buffer and Ligase), amplification (Duolink® Amplification buffer and Polymerase) and imaging using Zeiss Axio Widefield (20x/0.8) microscope. Human post mortem tissue sections were treated with TrueBlack (TrueBlack® Lipofuscin Autofluorescence Quencher) according to manufacturer's protocol, in order to eliminate lipofuscin autofluorescence before PLA. Murine tissue sections underwent an 
additional blocking step with anti-mouse IgG (Supplementary Table 1 ) for $1 \mathrm{~h}$ at $37^{\circ} \mathrm{C}$ to reduce nonspecific signal from goat anti-mouse MINUS.

\section{Western Blotting}

Cells were washed twice with cold PBS and scraped into ice cold 1X lysis buffer (Thermo Scientific, RIPA buffer) containing $1 \mathrm{X}$ protease and phosphatase inhibitors (Thermo Scientific, Halt ${ }^{\mathrm{TM}}$ Protease and Phosphatase Inhibitor Cocktail) and allowed to lyse, while rocking, at $4^{\circ} \mathrm{C}$ for $1 \mathrm{~h}$. Lysates were then cleared by centrifugation at 13,000 rpm for $20 \mathrm{~min}$. Supernatant was collected, and the protein was quantified using BioRad DC protein quantification assay. All samples were then diluted to a final concentration of $2 \mu \mathrm{g} / \mu \mathrm{L}$ with $1 \mathrm{X}$ Laemmli buffer. Samples were separated on 4-20\% BioRad TGX pre-packed gels at $100 \mathrm{~V}$ for $1 \mathrm{~h}$. Gels were transferred to a PVDF membrane using BioRad turbo transfer at $1.3 \mathrm{~A}$ for $7 \mathrm{~min}$. Next, membranes were washed $4 \mathrm{X}$ in PBS with $0.2 \%$ tween 20 and incubated in Odyssey Blocking buffer (Li-COR), $0.2 \%$ tween-20, and $0.1 \%$ SDS for $1 \mathrm{~h}$. Membranes were incubated overnight at $4{ }^{\circ} \mathrm{C}$ with Primary antibodies (Supplementary Table 1) and detected with fluorescent secondary antibodies (IRDye, Supplementary Table 1). Uniform regions of interest were applied to each lane to calculate total fluorescence intensity, which was representative of total target protein. Either Histone H3 (loading control) or Revert 700 stain (Revert 700 Total Protein, Li-COR) were used to calculate final relative protein expression for each lysate. Following Revert 700 stain, membranes were washed 2X with Revert 700 wash buffer (Li-COR) for 5 min each. Membranes were imaged using Li-COR ODYSSEY CLx scanner. Experimental data represent the average of 3 independent experiments.

\section{ELISA}


A Human $\alpha$ Syn oligomer ELISA kit (MyBioSource, MBS730762) was used to quantify of $\alpha$ Syn oligomer levels from cell samples treated with either PAR + BioPORTER or BioPORTER alone for $48 \mathrm{~h}$. Briefly, cells were washed 2X with PBS, scraped into ice cold 1X PBS, centrifuged at $1000 \mathrm{rpm}$ for $5 \mathrm{~min}$ and resuspended in $100 \mu \mathrm{L}$ of PBS. The resuspended cells were then lysed using a hand held sonicator for three pulses at $40 \%$ amplitude. $1 \mathrm{X}$ protease and phosphatase inhibitors were added to the lysate following sonication; the samples were kept on ice and immediately processed for protein quantification using DC protein quantification assay. All samples were diluted to a final concentration of $2.5 \mu \mathrm{g} / \mu \mathrm{L}$ and loaded into coated wells from the ELISA kit all steps were followed according to the manufacturer's protocol.

\section{A11 Immunodot Blot}

$2 \mu \mathrm{L}$ of cell lysates $(2.5 \mathrm{mg} / \mathrm{mL})$ were placed on a nitrocellulose membrane and allowed to air dry at RT for $1 \mathrm{~h}$. At this point, the membrane was incubated in Revert 700 protein stain for 10 min at RT and washed $2 \mathrm{X}$ with Revert 700 wash buffer for 5 min each. The membrane was imaged using Li-COR ODYSSEY CLx scanner at $700 \mathrm{~nm}$ to visualize total protein. After imaging, the membrane was washed for $5 \mathrm{~min}$ in Revert 700 reverse solution (Li-COR) in order to remove protein stain. The membrane was blocked using Odyssey blocking buffer for $1 \mathrm{~h}$ at RT and then incubated overnight at $4^{\circ} \mathrm{C}$ with $\mathrm{A} 11$, oligomer-specific antibody (Supplementary Table 1). Following overnight incubation, the membrane was washed $3 \mathrm{X}$ using PBS-T $(0.1 \%$ Tween-20). Secondary Antibody (Supplementary Table 1) was then added to the membrane and incubated at RT for $1 \mathrm{~h}$. After incubation, the membrane was washed 3X in PBST and processed for imaging.

\section{$\alpha$ Syn Protein Expression and Purification}


Protein expression and purification was done following previously published protocol $^{67}$. Briefly, the plasmid encoding the human $\alpha$ Syn sequence was transformed into Escherichia coli BL21(DE3) and the cells were grown on agar/LB plates with ampicillin $(100 \mu \mathrm{g} / \mathrm{mL})$ overnight at $37^{\circ} \mathrm{C}$. The next day a single colony was inoculated into $100 \mathrm{~mL}$ Luria-Bertani (LB) containing ampicillin $(100 \mu \mathrm{g} / \mathrm{mL})$. The culture was incubated at $37^{\circ} \mathrm{C}$ overnight with shaking at $\sim 200 \mathrm{rpm}$. The following day, $10 \mathrm{~mL}$ of the overnight culture was diluted with $1 \mathrm{~L}$ of $\mathrm{LB}$ media supplemented with ampicillin and this culture was incubated at $37^{\circ} \mathrm{C}$ until OD600 reached $0.6-$ 0.7. Protein expression was induced by addition of isopropyl- $\beta$-D-thiogalactoside (IPTG) to a final concentration of $1 \mathrm{mM}$ and continued to grow at $18^{\circ} \mathrm{C}$ overnight. After induction, cells were harvested by centrifugation at $4^{\circ} \mathrm{C}(20 \mathrm{~min}, 4,000 \mathrm{~g})$. The typical yield of wet-cell paste was $2 \mathrm{~g} / \mathrm{L}$. Cells were suspended in a lysis buffer $(5 \mathrm{~mL}$ for $1 \mathrm{~g}$ of cell paste) containing $25 \mathrm{mM}$ Tris, $20 \mathrm{mM}$ imidazole, $50 \mathrm{mM} \mathrm{NaCl}(\mathrm{pH}$ 8) with a protease inhibitor (phenylmethylsulfonylfluoride, $0.5 \mathrm{mM}$ final concentration and protease inhibitor cocktail from Cell Signaling Technology). Cells were lysed by sonication on ice for $10 \mathrm{~min}$ (20 s on, $20 \mathrm{~s}$ off). The crude cell lysate was then centrifuged at $20,000 \mathrm{~g}$ for $30 \mathrm{~min}$, and the supernatant was mixed with Ni-NTA resin (Clontech, $3 \mathrm{~mL}$ ) and kept on a rocker at RT for $30 \mathrm{~min}$. The resin was then washed with $100 \mathrm{~mL}$ wash buffer (25 mM Tris, $20 \mathrm{mM}$ imidazole, $50 \mathrm{mM} \mathrm{NaCl}$, pH 8). The protein was eluted with a buffer containing $25 \mathrm{mM}$ Tris, $300 \mathrm{mM}$ imidazole, $50 \mathrm{mM} \mathrm{NaCl}(\mathrm{pH}$ 8). Fractions containing the protein were identified by UV-Vis spectroscopy, combined and was treated with $\beta$-mercaptoethanol (200 mM final concentration) overnight at RT to cleave the Cterminal intein. The next day, the protein was concentrated to $3 \mathrm{~mL}$ and dialyzed against buffer containing $25 \mathrm{mM}$ Tris, $50 \mathrm{mM} \mathrm{NaCl}, \mathrm{pH}$. After dialysis, the protein mixture was loaded onto Ni-NTA column and the pure $\alpha$ Syn protein was collected in the flow through fractions. The 
combined protein fractions were concentrated and dialyzed against buffer containing $50 \mathrm{mM}$

Tris, $150 \mathrm{mM} \mathrm{NaCl}$, pH 7.5. The purity of the protein was confirmed by SDS-PAGE. Protein concentration was determined by measuring the absorbance at $280 \mathrm{~nm}$ and using the calculated (ExPASy) extinction coefficient of 5960 M-1cm-1.

\section{Site-directed Mutagenesis}

aSyn mutations were generated by performing site directed mutagenesis using the following primers:

\section{aSyn K43A}

Forward: 5'- TCCGCAACCAAGGAGGGA -3'

Reverse: 5'- TCCCTCCTTGGTTGCGGA - 3'

aSyn K43A K45A

Forward: 5'- GGCTCCGCAACCGCGGAGGGAGTG - 3'

Reverse: 5'- CACTCCCTCCGCGGTTGCGGAGCC - 3'

aSyn K58A

Forward: 5'-GTGGCTGAGGCGACCAAA - 3'

Reverse: 5'-TTTGGTCGCCTCAGCCAC - 3'

All plasmids and inserts were sequenced and confirmed to be free of any errors.

\section{PAR Binding Motifs (PBM)}

hxbxhhbbhhb (h are hydrophobic residues, $\mathrm{b}$ are basic residues, and $\mathrm{x}$ is any amino acid residue $)^{22} \cdot[\mathrm{HKR}]-\mathrm{X}-\mathrm{X}-[\mathrm{AIQVY}]-[\mathrm{KR}]-[\mathrm{KR}]-[\mathrm{AILV}]-[\mathrm{FILPV}]^{22,60}$.

\section{Preparation of $\alpha$ Syn fibrils}


Purified $\alpha$ Syn monomer $(100 \mu \mathrm{M})$ was incubated in buffer containing $50 \mathrm{mM}$ Tris $(\mathrm{pH} 7.5), 150$ $\mathrm{mM} \mathrm{NaCl}$ and $0.05 \% \mathrm{NaN} 3$ for $72 \mathrm{~h}$ at $37^{\circ} \mathrm{C}$ with shaking at $1000 \mathrm{rpm}$ in a Fisher Scientific Mixer. Fibrils with poly(ADP-ribose) (PAR) were prepared in the presence of $100 \mathrm{nM}$ PAR polymer (TREVIGEN) following the procedure described above.

\section{Transmission electron microscopy (TEM)}

The $100 \mu \mathrm{M}$ fibril stock solution was diluted $4 \mathrm{X}$ with water and samples $(5 \mu \mathrm{L})$ were spotted onto glow-discharged formvar/carbon-coated, 200-mesh copper grids (Ted Pella). After 1 min, grids were washed briefly with water and stained with one $10 \mu \mathrm{L}$ drop of $2 \% \mathrm{w} / \mathrm{v}$ uranyl acetate for $1 \mathrm{~min}$. The excess stain was removed by filter paper and the grids were dried under air. Samples were imaged with a Tecnai FEI T12 electron microscope at an acceleration voltage of $120 \mathrm{kV}$. Images were recorded on a Gatan OneView 4K Cmos camera.

\section{PAR Immunodot blot}

PAR-binding motif (PBM) were identified by aligning the PBM consensus to $\alpha$ Syn using the PATTINPROT search engine (NPS@PATTINPROT). For immunodot analysis, either $1 \mu \mathrm{g}$ fibrils, Histone H4 (positive control), or bovine serum albumin (negative control) were blotted onto a $0.2 \mu \mathrm{m}$ nitrocellulose membrane (Biorad). Membranes were left to dry for $60 \mathrm{~min}$, then incubated in DPBS supplemented with $0.05 \%$ Tween-20 (PBS-T) for $10 \mathrm{~min}$. The membrane was then incubated with $50 \mathrm{nM}$ PAR polymer in PBS-T for 2 hours with rocking at RT. The membrane was washed $5 \mathrm{X}$ with PBS-T (5 min each) and blocked with PBSMT (5\% milk in PBS-T) for 2 hours at RT. After the blocking step, the membrane was incubated in primary antibody (Supplementary Table 1) in PBS-T at $4{ }^{\circ} \mathrm{C}$ overnight. After 5 washes in PBSMT (5 min each), the membrane was incubated with secondary antibody (Supplementary Table 1) in 
PBSMT for 1 hour at RT. The membrane was washed $3 \mathrm{X}$ in PBSMT, $2 \mathrm{X}$ in PBS-T and 2X in DPBS (5 min each). The membrane was then imaged using Li-COR ODYSSEY CLx scanner. Spot intensities were measured using Image Studio software. Revert 700 protein stain was used for total protein staining measurement. Blotted membranes were incubated with protein stain for 5 min, rinsed with Revert 700 wash buffer, and imaged using Li-COR ODYSSEY CLx scanner.

\section{Thioflavin-T (ThT) assay}

Fluorescence spectra were obtained on an EnSpire Multimode Plate Reader (Perkin Elmer), using $440 \mathrm{~nm}$ as excitation wavelength. Samples were prepared by mixing protein and ThT in buffer (50 mM Tris, $150 \mathrm{mM} \mathrm{NaCl}, \mathrm{pH} 7.4)$ in a 96-well plate to a final concentration of $100 \mu \mathrm{M}$ and $10 \mu \mathrm{M}$, respectively. The plate was shaken at $1000 \mathrm{rpm}$ at $37{ }^{\circ} \mathrm{C}$ and fluorescence emission was measured at $490 \mathrm{~nm}$ over time.

\section{Molecular docking}

The PAR-dimer structure used in our studies was based on Lambrecht et al. ${ }^{68}$ and drawn on ChemDraw Profession 15.1 (PerkinElmer Informatics, Inc.). It was then imported to Chem3D Ultra 15.1 (PerkinElmer Informatics, Inc.) to minimize the PAR-dimer by MMFF94 force field for preparation of molecular docking. Molecular docking studies were performed via AutoDock $4.2^{69}$ plugin on PyMOL (pymol.org). Cryo-EM structure of MSA Type I $\alpha$ Syn fibril (PDB ID 6XYO, Resolution 2.6 ̊) was obtained from RCSB Protein Data Bank (www.rcsb.org). Polar hydrogens were added to the fibril structure. Non-polar hydrogens were removed from the PARdimer. A grid box with a dimension of $30 \times 30 \times 30 \AA^{3}$ was applied to the MSA Type I $\alpha$ Syn fibril structure covering the non-proteinaceous density pocket at the protofilament interface ${ }^{70}$. 
The Lamarckian Genetic Algorithm with a maximum of 2,500,000 energy evaluations was used to calculate $100 \alpha$ Syn fibril-PAR binding poses. The $\alpha$ Syn fibril-PAR complex with the most contacts and low free binding energy was reported.

\section{Quantification and Statistical Analysis}

All measurements were taken from distinct samples. Data points in each graph are mean $( \pm$ SEM); where " $n$ " indicates the number of biological replicates for each experiment. T-tests, oneway ANOVA, and two-way ANOVA followed by Tukey's post hoc test were performed and are described in each figure legend. Statistical significance was set at $\mathrm{P}<0.05$. All statistical analyses were carried out using Graphpad prism 8 software.

\section{Supplementary Information}

Supplementary Table 1: Antibody Information

Supplementary Table 2: Animal Information

Supplementary Table 3: Patient Information

Supplementary Table 4: Microscopy Settings

Acknowledgments: SH-SY5Y- $\alpha$ Syn cells were a gift from Dr. Harry Ischiropoulos, University of Pennsylvania. The plasmid encoding the human $\alpha$ Syn sequence was a gift from Dr. James Petersson, University of Pennsylvania. Funding: This research was supported by the Michael J. Fox Foundation (R.H.M.), U19-NS110456 (R.H.M.), T32GM008076 (L.N.P.) and supported in part by 1U19AG062418 (J.Q.T., V.M.Y.L., K.C.L.). Author contributions: L.N.P. performed all the cell-based studies and ex vivo animal and patient experiments, along with the 
computational protein alignment. Z.L.Z. helped produce all the purified proteins and fibrils used in this project. Z.L.Z performed TEM, ThT, and PAR immunodot blot analysis. L.N.P. and Z.L.Z. designed the primers for mutagenesis. J.Y.L. maintained cell cultures and aided in the experimental set-up for PLA. C.J.H. performed molecular docking studies. M.E.S. maintained $\alpha$ Syn protein expression and purification. K.J.E. provided assistance with PLA and transfection of Hela cells with EGFP- $\alpha$ Syn-A53T. K.C.L. provided support with animal model and experimental design. V.M.Y.L. and J.Q.T. provided support with experimental design and characterization of human post mortem brain tissue from PD/PDD and non-PD patients. Competing interests: The authors declare that they have no competing interests. Data and materials availability: All data generated and analyzed in this study are included in this published article and its extended data files.

\section{References:}

1 Maries, E., Dass, B., Collier, T. J., Kordower, J. H. \& Steece-Collier, K. The role of alpha-synuclein in Parkinson's disease: insights from animal models. Nat Rev Neurosci 4, 727-738, doi:10.1038/nrn1199 (2003).

2 Waxman, E. A. \& Giasson, B. I. Molecular mechanisms of alpha-synuclein neurodegeneration. Biochim Biophys 1792, 616-624, doi:10.1016/j.bbadis.2008.09.013 (2009).

3 Zeng, X.-S., Geng, W.-S., Jia, J.-J., Chen, L. \& Zhang, P.-P. Cellular and Molecular Basis of Neurodegeneration in Parkinson Disease. Front Aging Neurosci 10, 109-109, doi:10.3389/fnagi.2018.00109 (2018). 
4 Bridi, J. C. \& Hirth, F. Mechanisms of $\alpha$-Synuclein Induced Synaptopathy in Parkinson's Disease. Front Neurosci 12, doi:10.3389/fnins.2018.00080 (2018).

5 Lashuel, H. A., Overk, C. R., Oueslati, A. \& Masliah, E. The many faces of $\alpha$-synuclein: from structure and toxicity to therapeutic target. Nat Rev Neurosci 14, 38-48, doi:10.1038/nrn3406 (2013).

6 Kahle, P. J. et al. Subcellular Localization of Wild-Type and Parkinson's DiseaseAssociated Mutant $\alpha$-Synuclein in Human and Transgenic Mouse Brain. J Neurosci 20, 6365-6373, doi:10.1523/jneurosci.20-17-06365.2000 (2000).

7 Cabin, D. E. et al. Synaptic Vesicle Depletion Correlates with Attenuated Synaptic Responses to Prolonged Repetitive Stimulation in Mice Lacking a-Synuclein. J Neurosci 22, 8797-8807, doi:10.1523/jneurosci.22-20-08797.2002 (2002).

8 Murphy, D. D., Rueter, S. M., Trojanowski, J. Q. \& Lee, V. M.-Y. Synucleins Are Developmentally Expressed, and $\alpha$-Synuclein Regulates the Size of the Presynaptic Vesicular Pool in Primary Hippocampal Neurons. J Neurosci 20, 3214-3220, doi:10.1523/jneurosci.20-09-03214.2000 (2000).

9 Dettmer, U. et al. Parkinson-causing $\alpha$-synuclein missense mutations shift native tetramers to monomers as a mechanism for disease initiation. Nature communications $\mathbf{6}$, 7314-7314, doi:10.1038/ncomms8314 (2015).

10 Vermaas, J. V. \& Tajkhorshid, E. Conformational heterogeneity of $\alpha$-synuclein in membrane. Biochim Biophys Acta - Biomem 1838, 3107-3117, doi:https://doi.org/10.1016/j.bbamem.2014.08.012 (2014). 
11 Perez, R. G. \& Hastings, T. G. Could a loss of $\alpha$-synuclein function put dopaminergic neurons at risk? J Neurochem 89, 1318-1324, doi:10.1111/j.1471-4159.2004.02423.x (2004).

12 Spillantini, M. G. et al. $\alpha$-Synuclein in Lewy bodies. Nature 388, 839-840, doi:10.1038/42166 (1997).

13 Angelova, P. R. \& Abramov, A. Y. Alpha-synuclein and beta-amyloid - different targets, same players: calcium, free radicals and mitochondria in the mechanism of neurodegeneration. Biochem Biophys Res Co 483, 1110-1115, doi:https://doi.org/10.1016/j.bbrc.2016.07.103 (2017).

14 Rocha, E. M., De Miranda, B. \& Sanders, L. H. Alpha-synuclein: Pathology, mitochondrial dysfunction and neuroinflammation in Parkinson's disease. Neurobiol Dis 109, 249-257, doi:https://doi.org/10.1016/j.nbd.2017.04.004 (2018).

15 Outeiro, T. F. et al. Pharmacological inhibition of PARP-1 reduces $\alpha$-synuclein- and MPP+-induced cytotoxicity in Parkinson's disease in vitro models. Biochem Biophys Res Co 357, 596-602, doi:https://doi.org/10.1016/j.bbrc.2007.03.163 (2007).

16 Yunjong, L. et al. Poly (ADP-ribose) in the pathogenesis of Parkinson's disease. $B M B$ Rep. 47, 424-432 (2014).

17 Martire, S., Mosca, L. \& d'Erme, M. PARP-1 involvement in neurodegeneration: A focus on Alzheimer's and Parkinson's diseases. Mech Ageing Dev 146-148, 53-64, doi:https://doi.org/10.1016/j.mad.2015.04.001 (2015).

18 Cardinale, A., Paldino, E., Giampà, C., Bernardi, G. \& Fusco, F. R. PARP-1 Inhibition Is Neuroprotective in the R6/2 Mouse Model of Huntington's Disease. PLOS ONE 10, e0134482, doi:10.1371/journal.pone.0134482 (2015). 
19 Kim, S. H. et al. Widespread increased expression of the DNA repair enzyme PARP in brain in ALS. Neurol 62, 319-322, doi:10.1212/01.Wnl.0000103291.04985.Dc (2004).

20 Moroni, F. Poly(ADP-ribose)polymerase 1 (PARP-1) and postischemic brain damage. Curr Opin Pharmacol 8, 96-103, doi:https://doi.org/10.1016/j.coph.2007.10.005 (2008).

21 Luo, X. \& Kraus, W. L. On PAR with PARP: cellular stress signaling through poly(ADPribose) and PARP-1. Genes Dev 26, 417-432, doi:10.1101/gad.183509.111 (2012).

22 Pleschke, J. M., Kleczkowska, H. E., Strohm, M. \& Althaus, F. R. Poly(ADP-ribose) Binds to Specific Domains in DNA Damage Checkpoint Proteins. J Biol Chem 275, 40974-40980, doi:10.1074/jbc.M006520200 (2000).

23 Altmeyer, M. et al. Liquid demixing of intrinsically disordered proteins is seeded by poly(ADP-ribose). Nat Commun 6, 8088, doi:10.1038/ncomms9088 (2015).

24 Martire, S. et al. PARP-1 Modulates Amyloid Beta Peptide-Induced Neuronal Damage. PLOS ONE 8, e72169, doi:10.1371/journal.pone.0072169 (2013).

25 McGurk, L. et al. Poly(ADP-Ribose) Prevents Pathological Phase Separation of TDP-43 by Promoting Liquid Demixing and Stress Granule Localization. Mol Cell 71, 703717.e709, doi:https://doi.org/10.1016/j.molcel.2018.07.002 (2018).

26 Duan, Y. et al. PARylation regulates stress granule dynamics, phase separation, and neurotoxicity of disease-related RNA-binding proteins. Cell Res 29, 233-247, doi:10.1038/s41422-019-0141-z (2019).

27 Narne, P., Pandey, V., Simhadri, P. K. \& Phanithi, P. B. Poly(ADP-ribose)polymerase-1 hyperactivation in neurodegenerative diseases: The death knell tolls for neurons. Semin Cell Dev Biol 63, 154-166, doi:https://doi.org/10.1016/j.semcdb.2016.11.007 (2017). 
28 Kam, T.-I. et al. Poly(ADP-ribose) drives pathologic $\alpha$-synuclein neurodegeneration in Parkinson's disease. Science 362, eaat8407, doi:10.1126/science.aat8407 (2018).

29 Lábaj, J., Slamenová, D. \& Kosikova, B. Reduction of genotoxic effects of the carcinogen N-methyl-N'-nitro-N-nitrosoguanidine by dietary lignin in mammalian cells cultured in vitro. Nutr Cancer 47, 95-103, doi:10.1207/s15327914nc4701_12 (2003).

30 Carrozza, M. J., Stefanick, D. F., Horton, J. K., Kedar, P. S. \& Wilson, S. H. PARP inhibition during alkylation-induced genotoxic stress signals a cell cycle checkpoint response mediated by ATM. DNA Repair (Amst) 8, 1264-1272, doi:10.1016/j.dnarep.2009.07.010 (2009).

31 Gassman, N. R., Stefanick, D. F., Kedar, P. S., Horton, J. K. \& Wilson, S. H. Hyperactivation of PARP triggers nonhomologous end-joining in repair-deficient mouse fibroblasts. PLoS One 7, e49301, doi:10.1371/journal.pone.0049301 (2012).

32 Riad, A. et al. The Sigma-2 Receptor/TMEM97, PGRMC1, and LDL Receptor Complex Are Responsible for the Cellular Uptake of A $\beta 42$ and Its Protein Aggregates. Molecular Neurobiology, doi:10.1007/s12035-020-01988-1 (2020).

33 Liu, P. et al. Quaternary Structure Defines a Large Class of Amyloid- $\beta$ Oligomers Neutralized by Sequestration. Cell reports 11, 1760-1771, doi:10.1016/j.celrep.2015.05.021 (2015).

34 Kayed, R. et al. Fibril specific, conformation dependent antibodies recognize a generic epitope common to amyloid fibrils and fibrillar oligomers that is absent in prefibrillar oligomers. Mol Neurodegener 2, 18, doi:10.1186/1750-1326-2-18 (2007). 
35 James, D. I. et al. First-in-Class Chemical Probes against Poly(ADP-ribose) Glycohydrolase (PARG) Inhibit DNA Repair with Differential Pharmacology to Olaparib. ACS Chem Biol 11, 3179-3190, doi:10.1021/acschembio.6b00609 (2016).

36 Le May, N. et al. Poly (ADP-Ribose) Glycohydrolase Regulates Retinoic Acid ReceptorMediated Gene $\quad$ Expression. Mol Cell 48, 785-798, doi:https://doi.org/10.1016/j.molcel.2012.09.021 (2012).

37 Slama, J. T. et al. Specific Inhibition of Poly(ADP-ribose) Glycohydrolase by Adenosine Diphosphate (Hydroxymethyl)pyrrolidinediol. J Med Chem 38, 389-393, doi:10.1021/jm00002a021 (1995).

38 Luna, E. \& Luk, K. C. Bent out of shape: $\alpha$-Synuclein misfolding and the convergence of pathogenic pathways in Parkinson's disease. FEBS letters 589, 3749-3759, doi:10.1016/j.febslet.2015.10.023 (2015).

39 Breydo, L., Wu, J. W. \& Uversky, V. N. A-synuclein misfolding and Parkinson's disease. Biochim Biophys Acta 1822, 261-285, doi:10.1016/j.bbadis.2011.10.002 (2012).

40 Tran, H. T. et al. A-synuclein immunotherapy blocks uptake and templated propagation of misfolded $\alpha$-synuclein and neurodegeneration. Cell Rep 7, 2054-2065, doi:10.1016/j.celrep.2014.05.033 (2014).

41 Duda, J. E., Giasson, B. I., Mabon, M. E., Lee, V. M.-Y. \& Trojanowski, J. Q. Novel antibodies to synuclein show abundant striatal pathology in Lewy body diseases. Ann Neurol 52, 205-210, doi:10.1002/ana.10279 (2002).

42 Schaser, A. J. et al. Alpha-synuclein is a DNA binding protein that modulates DNA repair with implications for Lewy body disorders. Scientific Reports 9, 10919, doi:10.1038/s41598-019-47227-z (2019). 
43 Matta, E., Kiribayeva, A., Khassenov, B., Matkarimov, B. T. \& Ishchenko, A. A. Insight into DNA substrate specificity of PARP1-catalysed DNA poly(ADP-ribosyl)ation. Scientific Reports 10, 3699, doi:10.1038/s41598-020-60631-0 (2020).

44 Weaver, A. \& Yang, E. Beyond DNA Repair: Additional Functions of PARP-1 in Cancer. Frontiers in Oncology 3, doi:10.3389/fonc.2013.00290 (2013).

45 Wang, Y. et al. Poly(ADP-ribose) (PAR) binding to apoptosis-inducing factor is critical for PAR polymerase-1-dependent cell death (parthanatos). Science signaling 4, ra20ra20, doi:10.1126/scisignal.2000902 (2011).

46 Tenreiro, S., Eckermann, K. \& Outeiro, T. F. Protein phosphorylation in neurodegeneration: friend or foe? Front Mol Neurosci 7, 42-42, doi:10.3389/fnmol.2014.00042 (2014).

47 Anderson, J. P. et al. Phosphorylation of Ser-129 Is the Dominant Pathological Modification of $\alpha$-Synuclein in Familial and Sporadic Lewy Body Disease. J Biol Chem 281, 29739-29752, doi:10.1074/jbc.M600933200 (2006).

48 Wang, Y. et al. Phosphorylated $\alpha$-Synuclein in Parkinson's Disease. Sci Transl Med 4, 121ra120-121ra120, doi:10.1126/scitranslmed.3002566 (2012).

49 Oueslati, A. Implication of Alpha-Synuclein Phosphorylation at S129 in Synucleinopathies: What Have We Learned in the Last Decade? J Parkinsons Dis 6, 3951, doi:10.3233/JPD-160779 (2016).

50 Kim, W. S., Kågedal, K. \& Halliday, G. M. Alpha-synuclein biology in Lewy body diseases. Alz Res Therapy 6, 73, doi:10.1186/s13195-014-0073-2 (2014). 
51 Wakabayashi, K., Yoshimoto, M., Tsuji, S. \& Takahashi, H. $\alpha$-Synuclein immunoreactivity in glial cytoplasmic inclusions in multiple system atrophy. Neurosci Lett 249, 180-182, doi:https://doi.org/10.1016/S0304-3940(98)00407-8 (1998).

52 Leung, A. K. L. Poly(ADP-ribose): an organizer of cellular architecture. The Journal of cell biology 205, 613-619, doi:10.1083/jcb.201402114 (2014).

53 David, K. K., Andrabi, S. A., Dawson, T. M. \& Dawson, V. L. Parthanatos, a messenger of death. Frontiers in bioscience (Landmark edition) 14, 1116 (2009).

54 Gagné, J. P. et al. Quantitative proteomics profiling of the poly(ADP-ribose)-related response to genotoxic stress. Nucleic Acids Res 40, 7788-7805, doi:10.1093/nar/gks486 (2012).

55 Klingstedt, T. et al. Luminescent conjugated oligothiophenes distinguish between $\alpha$ synuclein assemblies of Parkinson's disease and multiple system atrophy. Acta Neuropathologica Communications 7, 193, doi:10.1186/s40478-019-0840-1 (2019).

56 Alam, M. S. Proximity Ligation Assay (PLA). Curr Protoc Immunol 123, e58-e58, doi:10.1002/cpim.58 (2018).

57 Wang, Z., Gagné, J.-P., Poirier, G. G. \& Xu, W. Crystallographic and Biochemical Analysis of the Mouse Poly(ADP-Ribose) Glycohydrolase. PLOS ONE 9, e86010, doi:10.1371/journal.pone.0086010 (2014).

58 Bétemps, D. et al. Alpha-synuclein spreading in M83 mice brain revealed by detection of pathological $\alpha$-synuclein by enhanced ELISA. Acta Neuropathol Commun 2, 29-29, doi:10.1186/2051-5960-2-29 (2014). 
59 Li, J., Uversky, V. N. \& Fink, A. L. Conformational Behavior of Human $\alpha$-Synuclein is Modulated by Familial Parkinson's Disease Point Mutations A30P and A53T. NeuroToxicol 23, 553-567, doi:https://doi.org/10.1016/S0161-813X(02)00066-9 (2002).

60 Gagné, J.-P. et al. Proteome-wide identification of poly(ADP-ribose) binding proteins and poly(ADP-ribose)-associated protein complexes. Nucleic Acids Res 36, 6959-6976, doi:10.1093/nar/gkn771 (2008).

61 Schweighauser, M. et al. Structures of $\alpha$-synuclein filaments from multiple system atrophy. Nature, doi:10.1038/s41586-020-2317-6 (2020).

62 McQuin, C. et al. CellProfiler 3.0: Next-generation image processing for biology. PLOS Biology 16, e2005970, doi:10.1371/journal.pbio.2005970 (2018).

63 Mazzulli, J. R. et al. Cytosolic catechols inhibit alpha-synuclein aggregation and facilitate the formation of intracellular soluble oligomeric intermediates. J Neurosci 26, 10068-10078, doi:10.1523/JNEUROSCI.0896-06.2006 (2006).

64 Robinson, J. L. et al. Neurodegenerative disease concomitant proteinopathies are prevalent, age-related and APOE4-associated. Brain 141, 2181-2193, doi:10.1093/brain/awy146 (2018).

65 Brettschneider, J., Del Tredici, K., Lee, V. M. Y. \& Trojanowski, J. Q. Spreading of pathology in neurodegenerative diseases: a focus on human studies. Nat Rev Neurosci 16, 109-120, doi:10.1038/nrn3887 (2015).

66 Toledo, J. B. et al. A platform for discovery: The University of Pennsylvania Integrated Neurodegenerative Disease Biobank. Alzheimers Dement 10, 477-484.e471, doi:10.1016/j.jalz.2013.06.003 (2014). 
67 Lengyel-Zhand, Z. et al. Synthesis and characterization of high affinity fluorogenic $\alpha$ synuclein probes. Chem Commun, doi:10.1039/C9CC09849F (2020).

68 Lambrecht, M. J. et al. Synthesis of Dimeric ADP-Ribose and Its Structure with Human Poly(ADP-ribose) Glycohydrolase. J Am Chem Soc 137, 3558-3564, doi:10.1021/ja512528p (2015).

69 Morris, G. M. et al. AutoDock4 and AutoDockTools4: Automated docking with selective receptor flexibility. J Comput Chem 30, 2785-2791, doi:10.1002/jcc.21256 (2009). 


\section{Main Figures:}

a

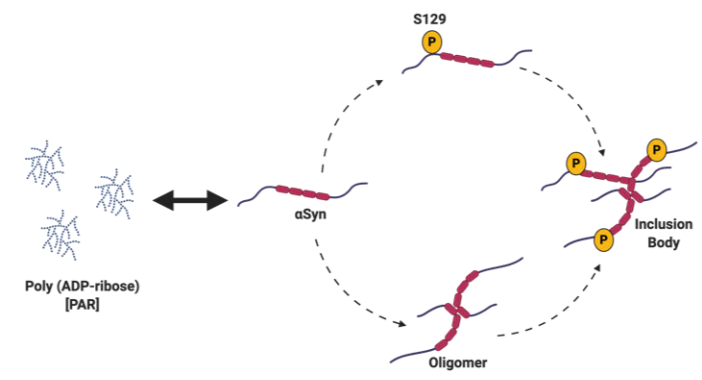

C

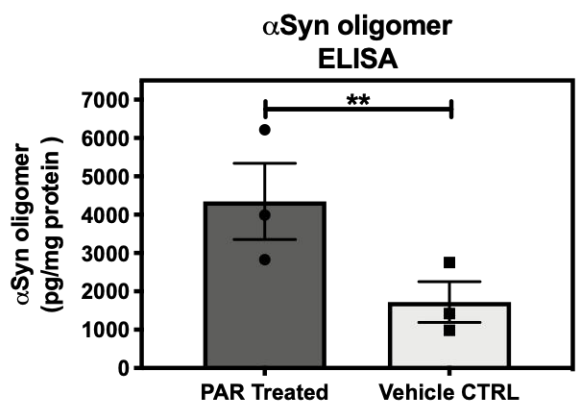

d

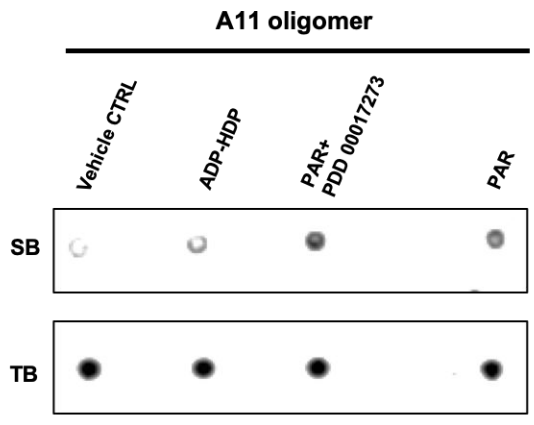

b

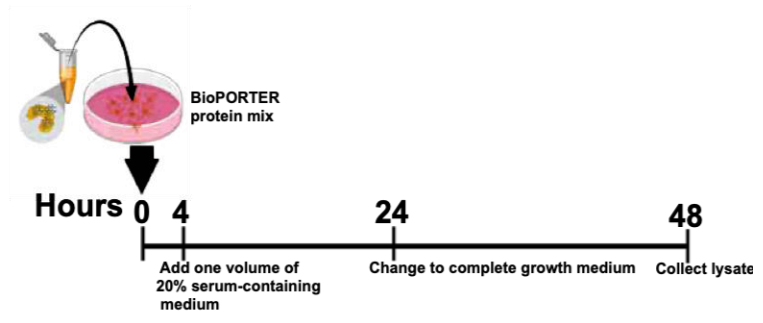

e

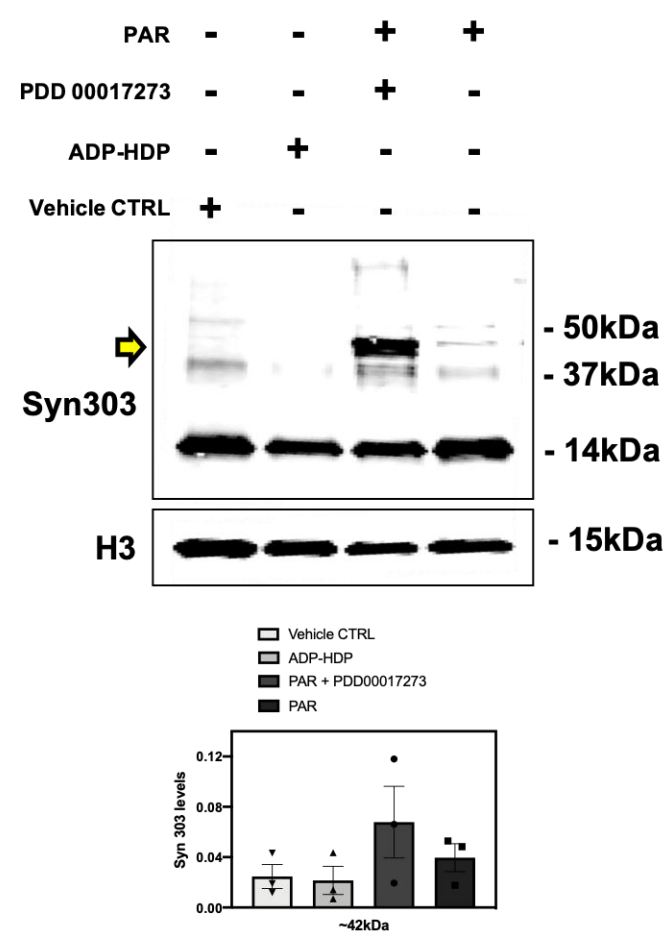

Figure 1. PAR seeds monomeric aSyn aggregation. (a) Proposed molecular mechanism of PAR induced $\alpha$ Syn aggregation (b) Experimental scheme of BioPORTER-mediated transfection of PAR polymer into SH-SY5Y- $\alpha$ Syn neuroblastoma cells. (c) Human $\alpha$ Syn oligomer-specific ELISA on cell lysates from SH-SY5Y- $\alpha$ Syn cells treated with $50 \mathrm{nM}$ PAR vs BioPORTER alone (vehicle control). Bars represent mean \pm SEM. Student's one-tailed t test $(\mathrm{n}=3)$. $* * \mathrm{P}=0.003$. $\mathrm{R}^{2}=0.53$. d.f. $=10$. (d) Representative Immunodot blot of an oligomer-specific antibody (A11) used to measure specific binding (SB) i.e. oligomeric content in PAR, PAR $+1 \mu \mathrm{M}$ PDD00017273 (PARGi), and ADP-HDP treated cell lysates vs. BioPORTER alone (vehicle control). A total protein stain (Revert 700) was used to assess total binding (TB). Experiments were repeated independently three times $(\mathrm{n}=3)$. (e) Representative Western blot (top) and semi-quantitative analysis of higher molecular weight ( $\sim 42 \mathrm{kDa}) \alpha$ Syn aggregation levels using conformation-specific Syn 303 antibody (bottom). Bars represent means \pm SEM. One-way ANOVA $(\mathrm{n}=3)$. $\mathrm{P}=\mathrm{ns}$. Histone 3 (H3) was used as a loading control. 
a

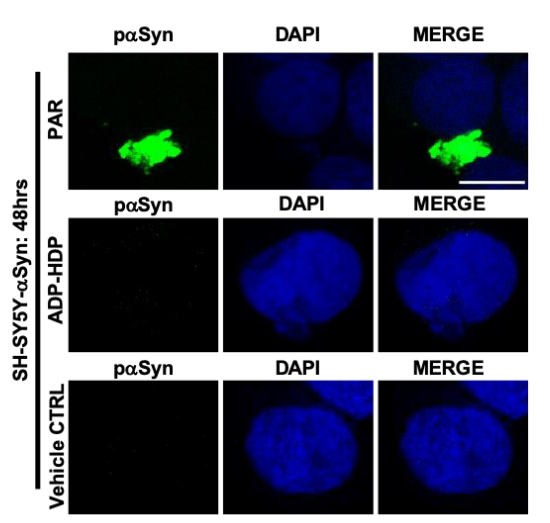

b

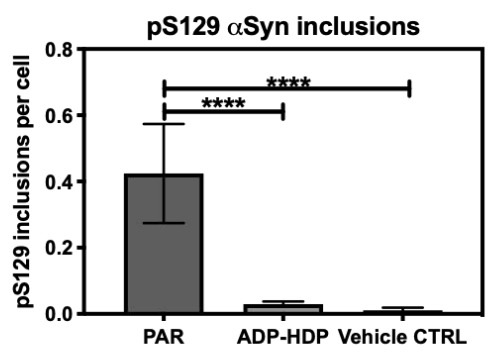

C

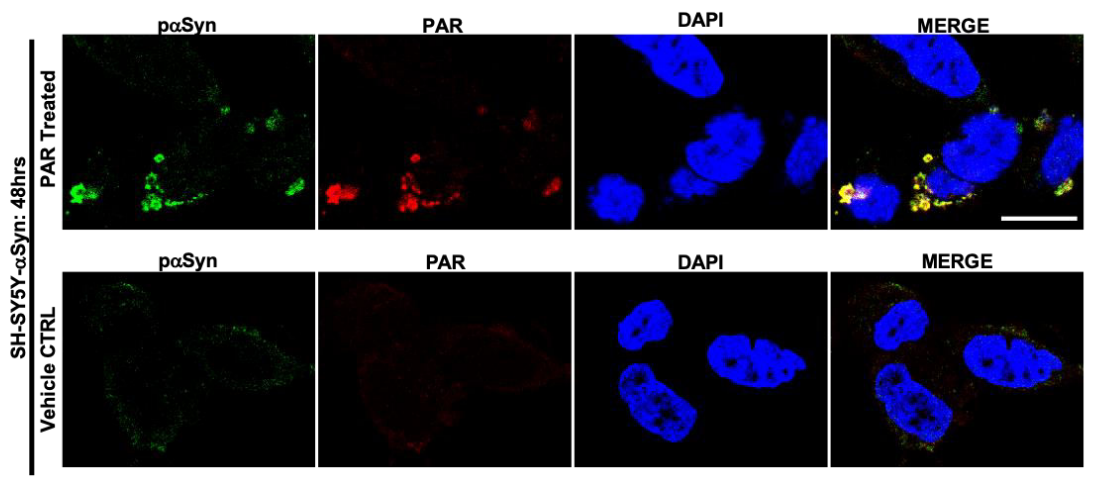

d

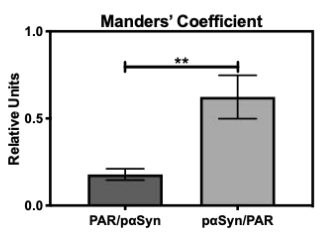

e

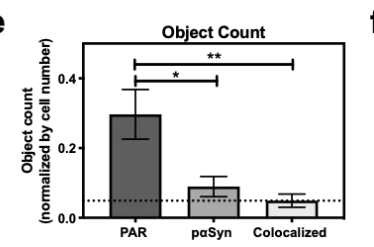

f

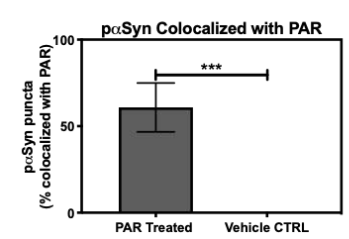

Figure 2. PAR promotes the formation of $\alpha \mathrm{Syn}$ inclusion aggregates. (a) Representative immunostain of paSyn (green) and DAPI (blue) in SH-SY5Y- $\alpha$ Syn cells $48 \mathrm{~h}$ post treatment with either $50 \mathrm{nM}$ PAR or ADP-HDP vs. BioPORTER alone (vehicle control). (b) Quantification of $\mathrm{p} \alpha \mathrm{Syn}$ inclusions (aggregates larger than $1 \mu \mathrm{m}$ ) in PAR treated, ADP-HDP treated, and BioPORTER alone (vehicle control) samples. Bars represent means \pm SEM. Two-way ANOVA followed by Tukey's post hoc test $(\mathrm{n}=3)$. $* * * * \mathrm{P}<0.0001$. (c) Representative IF immunostain of $\mathrm{p} \alpha \mathrm{Syn}$ (green), PAR polymer (red) and DAPI (blue) in SH-SY5Y- $\alpha$ Syn cells $48 \mathrm{~h}$ post treatment with either 50nM PAR vs. BioPORTER alone (vehicle control). Scale bar $10 \mu \mathrm{m}$. (d) Manders' overlap coefficient analysis (where an overlap coefficient of 0.5 implies that $50 \%$ of both objects, i.e. pixels, overlap) between PAR over p $\alpha$ Syn inclusions (PAR/paSyn) against paSyn inclusions over PAR ( $\mathrm{p} \alpha \mathrm{Syn} / \mathrm{PAR})$. Bars represent means \pm SEM. Student's two-tailed $\mathrm{t}$ test $(\mathrm{n}=3)$. ${ }^{* * P}<0.002$ (e) Object count analysis normalized by DAPI count i.e. cell number. Bars represent means \pm SEM indicating total object counts for PAR, p $\alpha$ Syn inclusions, and total colocalized objects. The graph indicates that most paSyn immunostain was colocalized with PAR, but a significant amount of PAR was not colocalized with paSyn. Two-way ANOVA followed by Tukey's post hoc test (n $=3$ ). ${ }^{*} \mathrm{P}<0.03, * * \mathrm{P}<0.002$ (f) Colocalization analysis comparing the number of paSyn inclusions colocalized with PAR immunostain in PAR treated and BioPORTER alone (vehicle control) samples. Images were captured using Zeiss LSM 710 confocal (40x/1.4 Oil) microscope. Bars represent means \pm SEM. Student's two-tailed t test $(\mathrm{n}=3)$. $* * * \mathrm{P}<0.0005$. Scale bar $10 \mu \mathrm{m}$. 
A

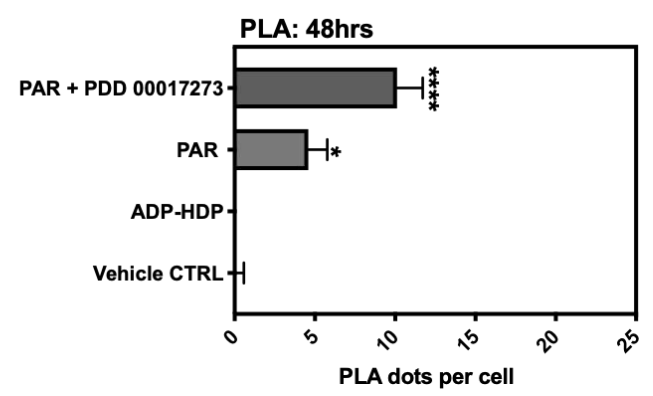

C

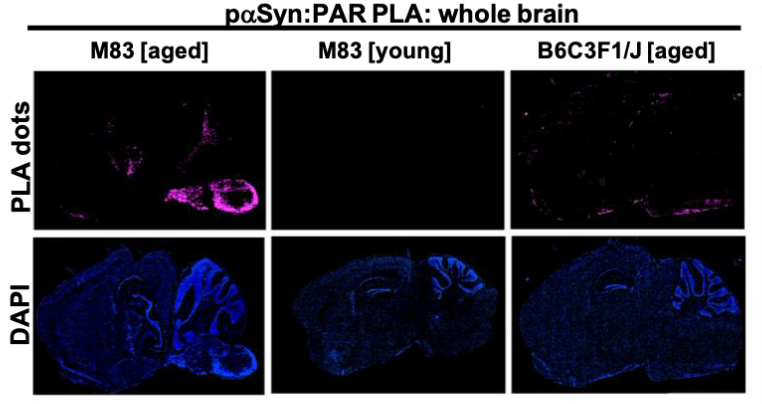

E

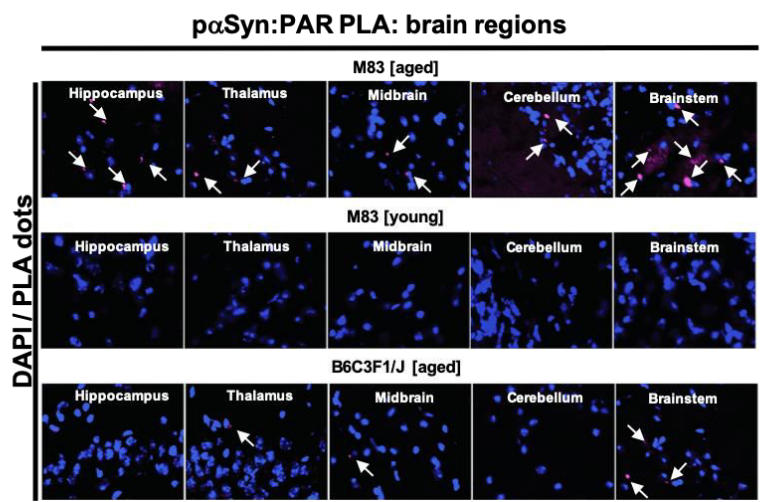

B

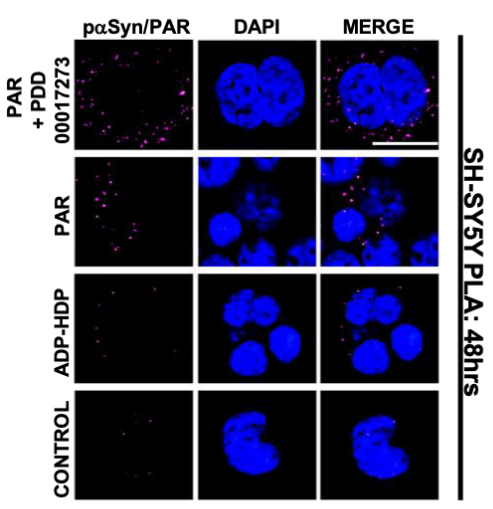

D

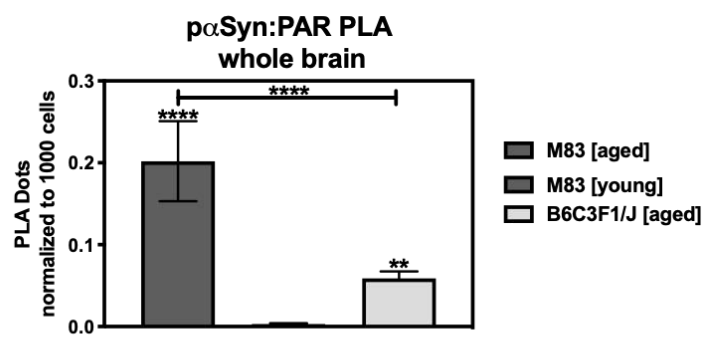

$\mathbf{F}$

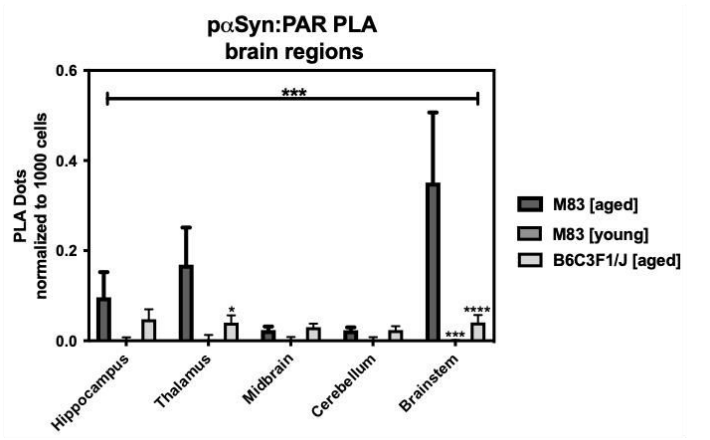

Figure 3. PAR interacts with phosphorylated (S129) $\alpha$ Syn in pathological settings. (a) Quantification from proximity ligation assays (PLA) measuring paSyn and PAR interactions in SH-SY5Y- $\alpha$ Syn cells 48 $\mathrm{h}$ post treatment with either PAR, PAR $+1 \mu \mathrm{M}$ PDD00017273 (PARGi) or ADP-HDP vs. BioPORTER alone (vehicle control). Bars represent means \pm SEM. Two-way ANOVA followed by Tukey's post hoc test $(\mathrm{n}=3) .{ }^{*} \mathrm{P}<0.03, * * * * \mathrm{P}<0.0001$ (b) Representative DAPI and PLA ROI images showing PLA dots (pink); these dots indicate direct interactions between $\alpha$ Syn and PAR in PAR treated, ADP-HDP treated and BioPORTER alone (vehicle control) samples. Scale bar $10 \mu \mathrm{m}$. (c) Representative DAPI (bottom panel) and PLA (top panel) whole brain images from M83 Tg aged, M83 Tg young, and B6C3F1/J aged mice ( $\mathrm{n}=3$ mice per group). (d) Quantification of whole brain PLA levels in M83 Tg aged, M83 Tg young and B6C3F1/J mice $(\mathrm{n}=3)$. Each bar represents means \pm SEM. One-way ANOVA. **P $<0.002$, $* * * * \mathrm{P}<0.0001$ (e) Representative PLA staining (white arrows) of ROIs obtained from 20x merge images. (f) Quantification of different brain regions in M83 Tg aged, M83 Tg young, and B6C3F1/J aged mice. Images were captured using Zeiss Axio Widefield (20x/0.8) microscope. Bars represent means \pm SEM. Two-way ANOVA followed by Tukey's post hoc test $(\mathrm{n}=3) . * * \mathrm{P}<0.002, * * * \mathrm{P}<0.0002$, ****P $<0.0001$. 

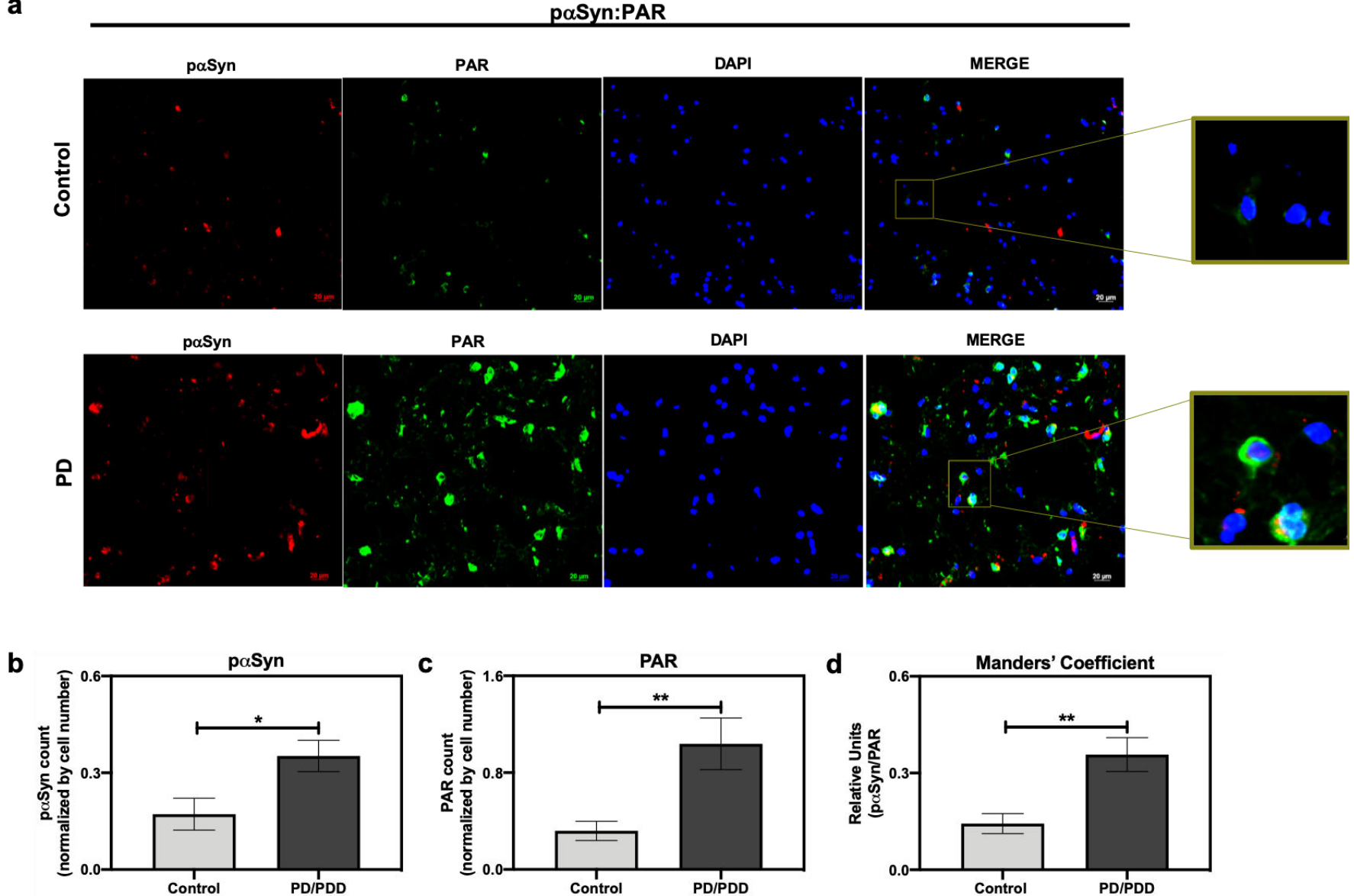

Figure 4. Increased S129 paSyn and PAR levels in PD/PDD patient samples. (a) Representative IF immunostain of paSyn (red), PAR (green), and DAPI (blue) in non-PD control (top panel, tissue ID 121111) and PD/PDD (bottom panel, tissue ID 116441) patient samples. Merge channel regions of interest (ROI) show colocalization between paSyn and PAR staining. Scale bar $20 \mu \mathrm{m}$. Images were captured using Zeiss Axio Widefield (20x/0.8) microscope. (b) Quantification of paSyn levels, normalized by DAPI count, in control vs. PD/PDD patients. (c) Quantification of PAR levels, normalized by DAPI count, in control vs. PD/PDD patients. (d) Quantification of paSyn/PAR overlap in control vs. $\mathrm{PD} / \mathrm{PDD}$ patients using Manders' overlap coefficient. Bars represent means \pm SEM. Student's two-tailed $\mathrm{t}$ test ( $\mathrm{n}=3$ to 4 patient samples per group). $* \mathrm{P}<0.03, * * \mathrm{P}<0.002$. 


\section{paSyn:PAR PLA}

a
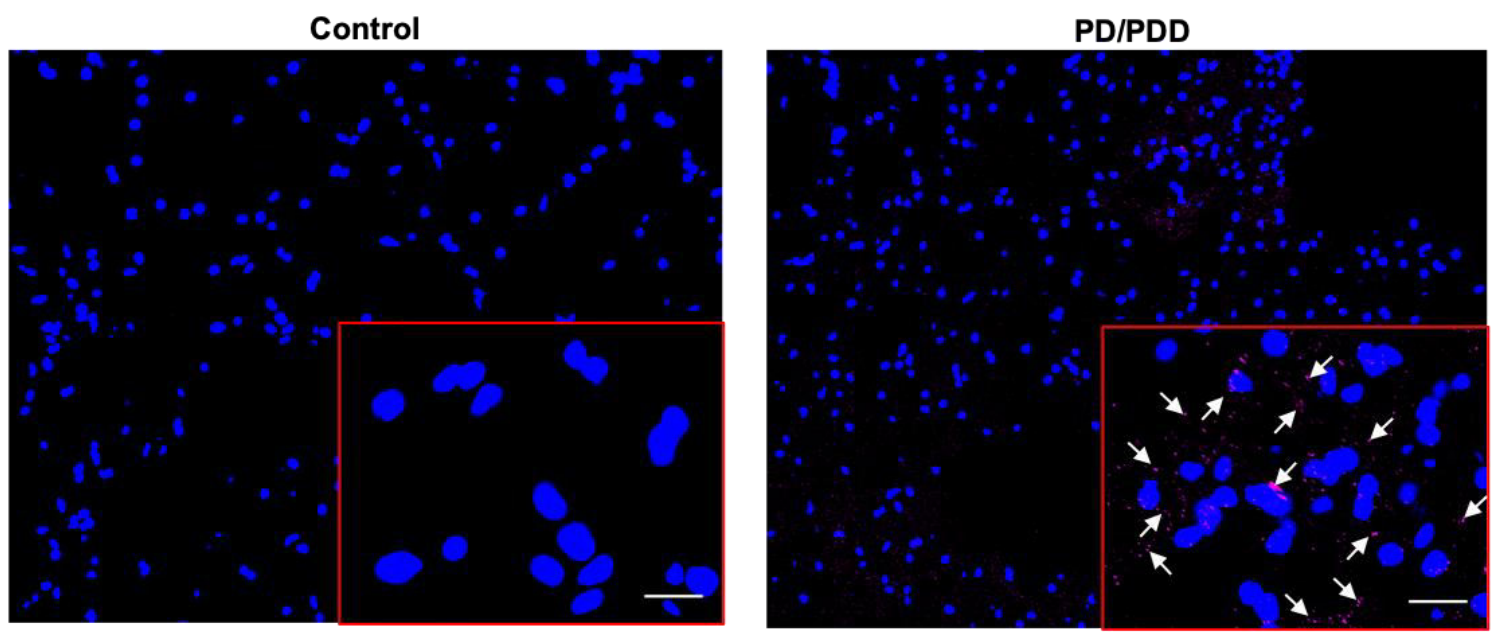

b

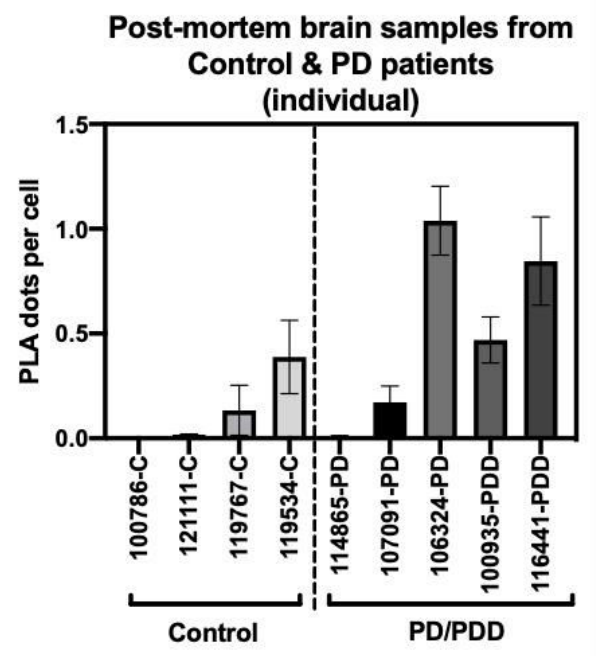

C

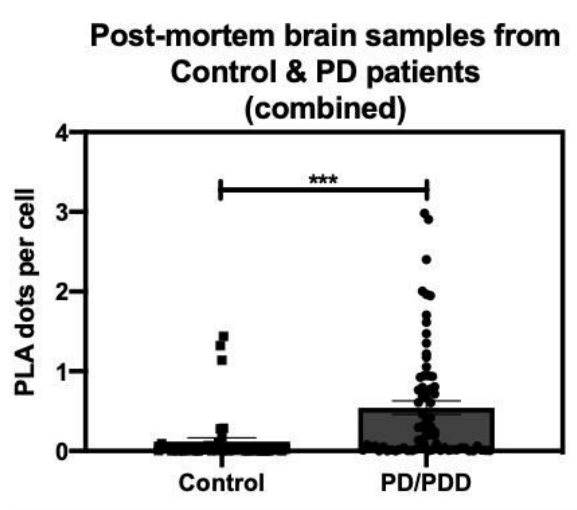

Figure 5. PAR predominantly interacts with paSyn in PD/PDD post mortem patient samples. (a) Representative PLA and DAPI images in non-PD control (top panel, tissue ID 121111) and PD/PDD patient samples (bottom panel, tissue ID 116441). ROI overlaid on merge channel. ROI scale bar $10 \mu \mathrm{m}$. Images were captured using Zeiss Axio Widefield (20x/0.8) microscope. Representative white arrows showing PLA positive signal (b) Quantification of individual PLA dot count in non-PD control vs. PD/PDD patient samples. Bars represent means \pm SEM. (c) Combined PLA analysis for all control and PD/PDD tissue samples, whereby each graphical symbol (black circle) represents the average number of PLA dots normalized to cell count (DAPI) for each field-of-view. 15 fields were captured for each patient sample. Student's two-tailed t test $(\mathrm{n}=3$ to 4 patient samples per group). $* * * \mathrm{P}<0.0005$. 
a

C
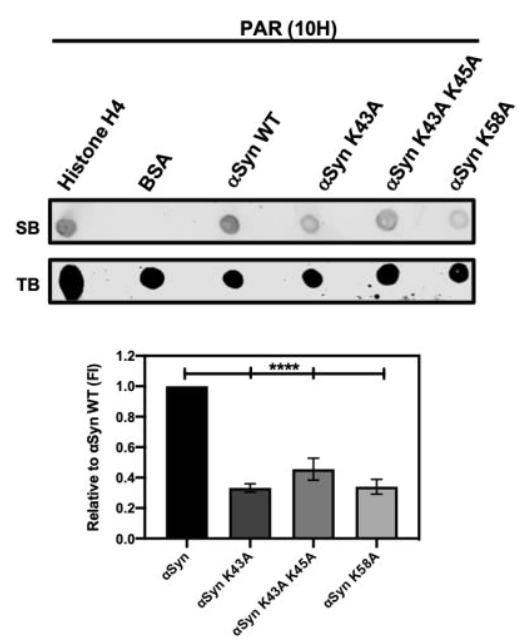

Site : $48-58$

A $\frac{\mathrm{PBM}}{59 \%}$ b

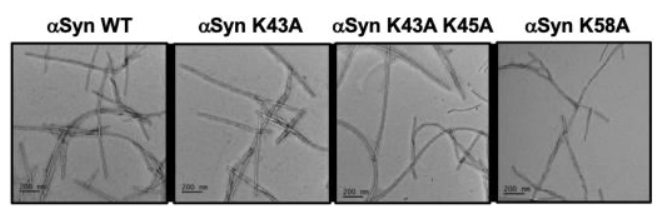

d
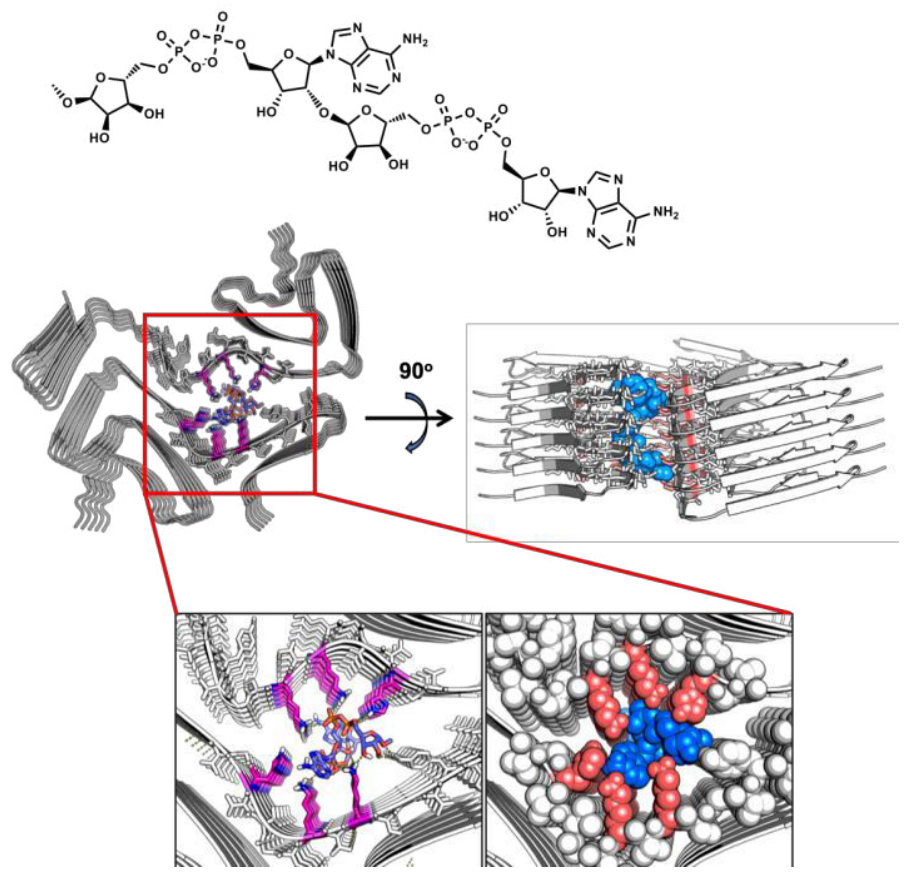

Figure 6. PAR interacts with $\alpha$ Syn via electrostatic forces in the $\mathbf{N}$-terminal region of the protein. (a) Alignment of the full $\alpha$ Syn sequence with PBMs yielded a 59\% PAR-binding probability at amino acid residues 43-54 and 48-58 on $\alpha$ Syn. Lysine amino acid residues (red) at the two sites were substituted to neutral alanine residues. (b) Three mutants of $\alpha$ Syn were generated with compromised PAR-binding sites. Two of the $\alpha$ Syn mutants had a point mutation at amino acid residues K43 \& K58 respectively, while the third mutant had two point mutations at positions K43 and K45. All mutants were fully fibrillated within $72 \mathrm{hr}$. Scale bar $200 \mathrm{~nm}$. (c) PAR immunodot blot (top), whereby WT and mutant $\alpha$ Syn fibrils were spotted onto a membrane, along with, histone H4 (positive control), and BSA (negative control) and incubated with PAR polymer to assess PAR binding. Semi-quantitative analysis (bottom) of WT and mutant $\alpha$ Syn fibril signal intensity normalized to WT $\alpha$ Syn signal. One-way ANOVA ( $=3$ ). $* * * * \mathrm{P}<0.0001$. (d) Chemical structure of PAR-dimer used in molecular docking studies. (e) Cryo-EM structure of MSA Type I $\alpha$ Syn fibril interacting with the PAR-dimer complex with a low free binding energy of $-15.6 \mathrm{kcal} / \mathrm{mol}$. 


\section{Extended Data}

a

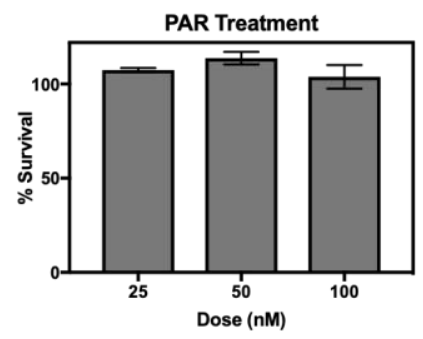

c
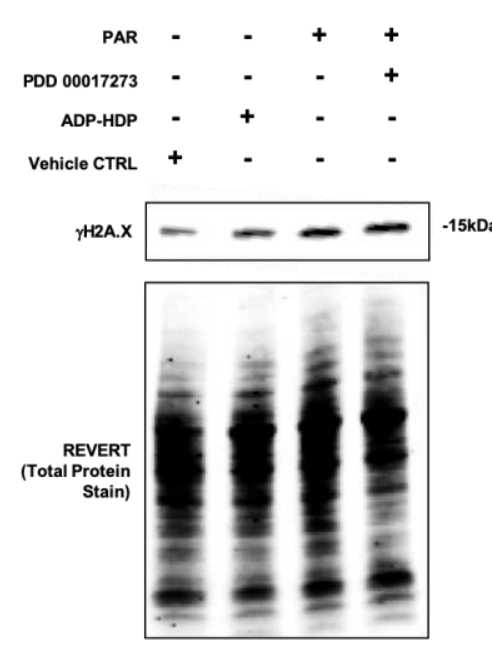

$\square$ PAR + PDD 00017273

$\square$ PAR

$\square$ ADP-HDP

$\square$ Vehicle CTRL

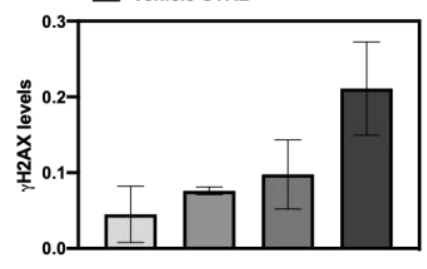

b

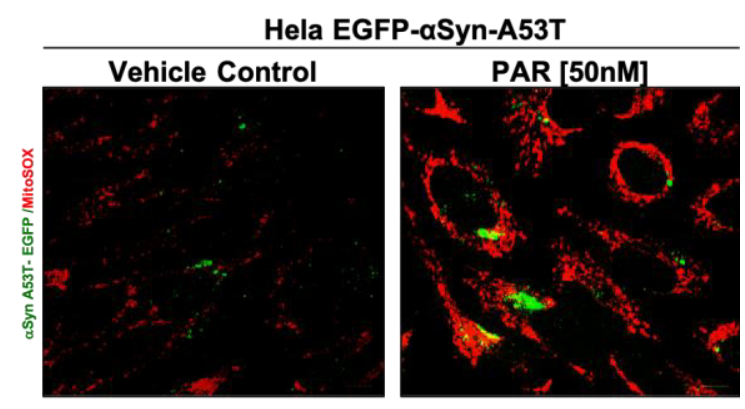

d

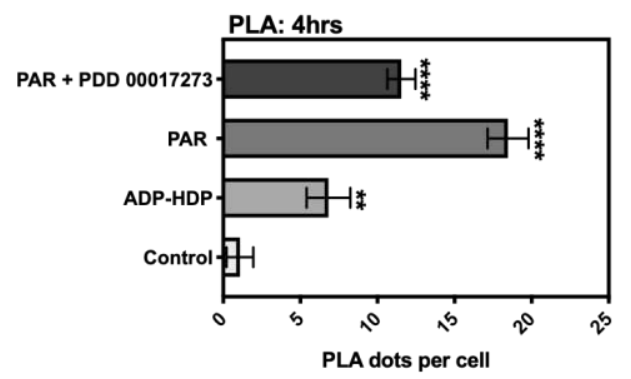

e

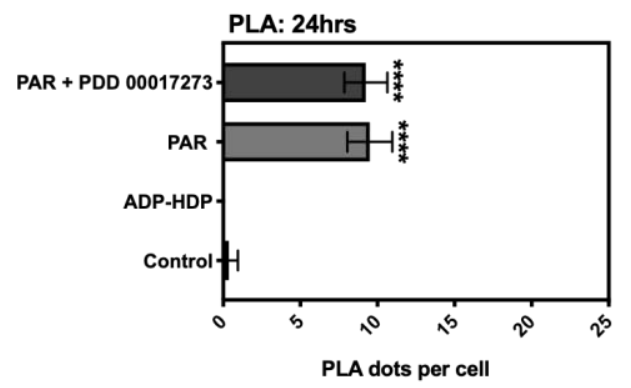

Extended Data Fig 1. Intracellular effects of PAR on aSyn. (a) Cytotoxicity assay on SH-SY5Y neuroblastoma cells treated in triplicate with three different concentrations of PAR polymer for $48 \mathrm{~h}$. (b) Hela cells transfected with EGFP- $\alpha$ Syn-A53T and treated with PAR $(50 \mathrm{nM})$ for $48 \mathrm{~h}$; representative ROIs from merge channel images showing $\alpha$ Syn A53T-EGFP (green) and increased superoxide levels i.e. higher red intensity, in the PAR treated vs. BioPORTER alone (vehicle control) cells. Images were captured using Zeiss Axio Widefield (20x/0.8) microscope. Experiments were performed in triplicate. (c) Representative Western blot and graph of $\gamma \mathrm{H} 2 \mathrm{AX}$ levels in PAR, PAR $+1 \mu \mathrm{M}$ PDD00017273 (PARGi) and ADP-HDP treated SH-SY5Y- $\alpha$ Syn cells. Experiments were repeated independently three times (n $=3$ ). (d and e) Quantification data from a time course PLA on SH-SY5Y- $\alpha$ Syn cells treated with PAR, PAR + $1 \mu \mathrm{M}$ PDD00017273 (PARGi) or ADP-HDP for $4 \mathrm{~h}$ (d) and $24 \mathrm{~h}$ (e). Bars represent means \pm SEM. Two-way ANOVA followed by Tukey's post hoc test $(\mathrm{n}=3)$. **** $\mathrm{P}<0.0001$. 
a

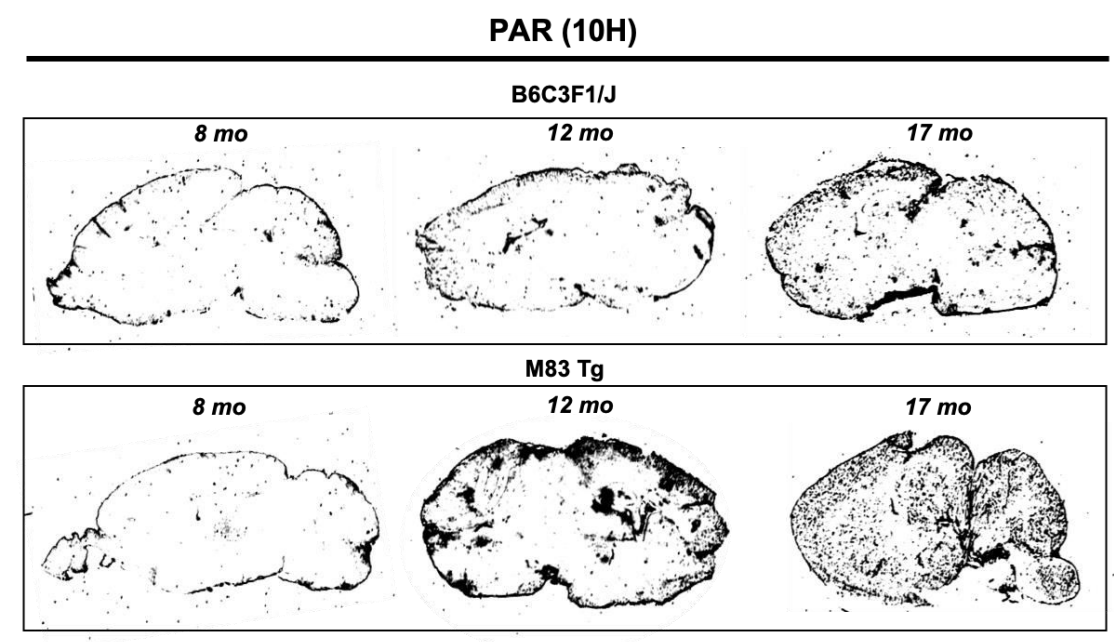

b
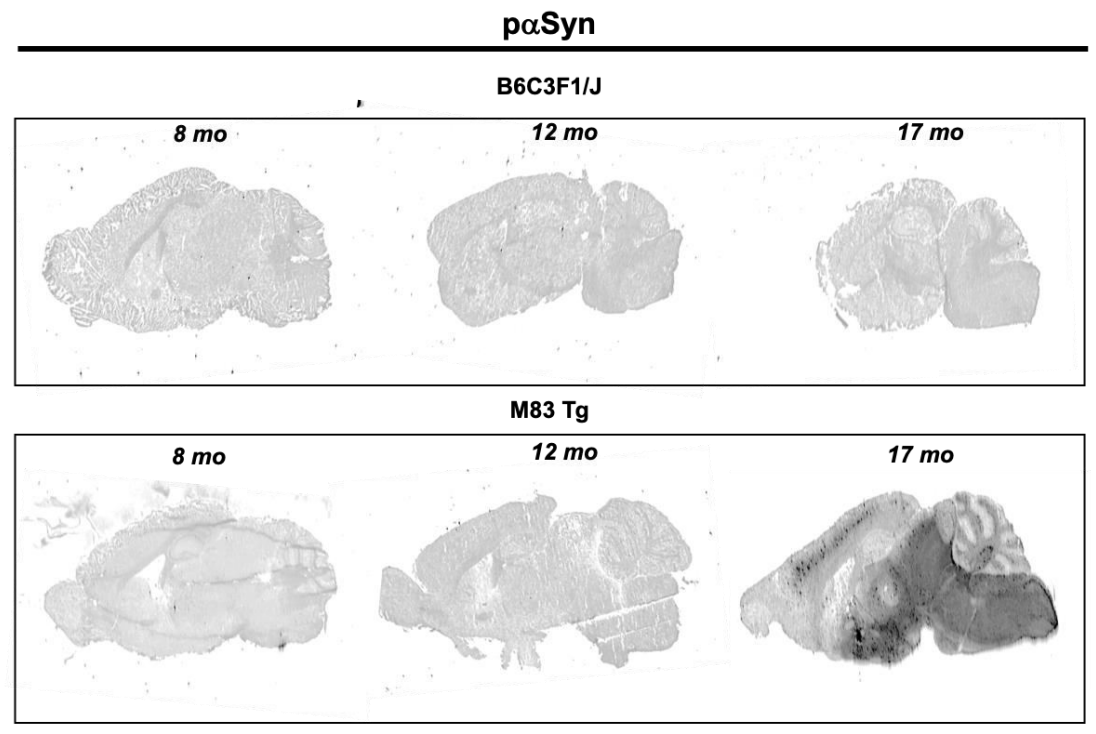

C

PLA

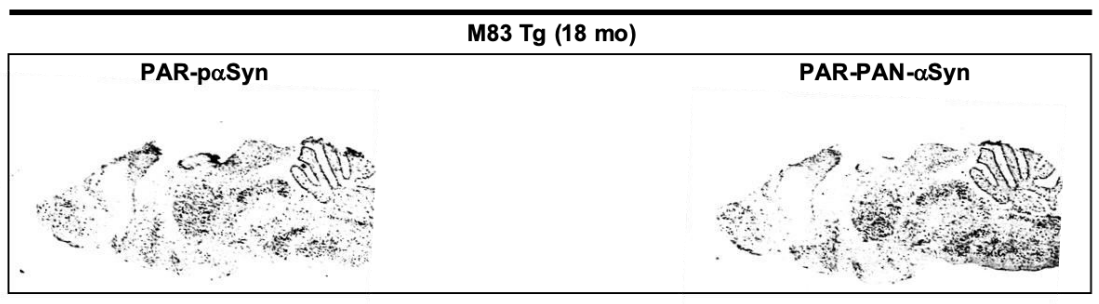

Extended Data Fig 2. Characterization of PAR and paSyn expression in murine brain sections. Representative images of endogenous PAR (a) and paSyn (b) levels in sagittal brain sections from B6C3F1/J (top panel) and M83 Tg (bottom panel) mice at three different age groups (8 mo, 12 mo, and 17 mo). (c) PLA on PAR-paSyn (left) and PAR-PAN- $\alpha$ Syn (right) sagittal brain sections from M83 Tg mice at 18 mo of age. All sections were $10 \mu \mathrm{m}$ thick and all images were captured using a Li-COR ODYSSEY CLX scanner. 
a

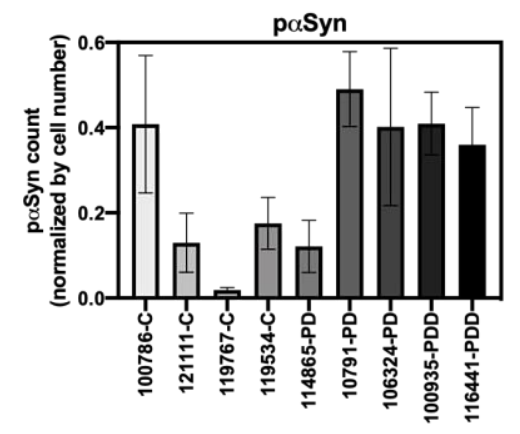

Patient Samples

c

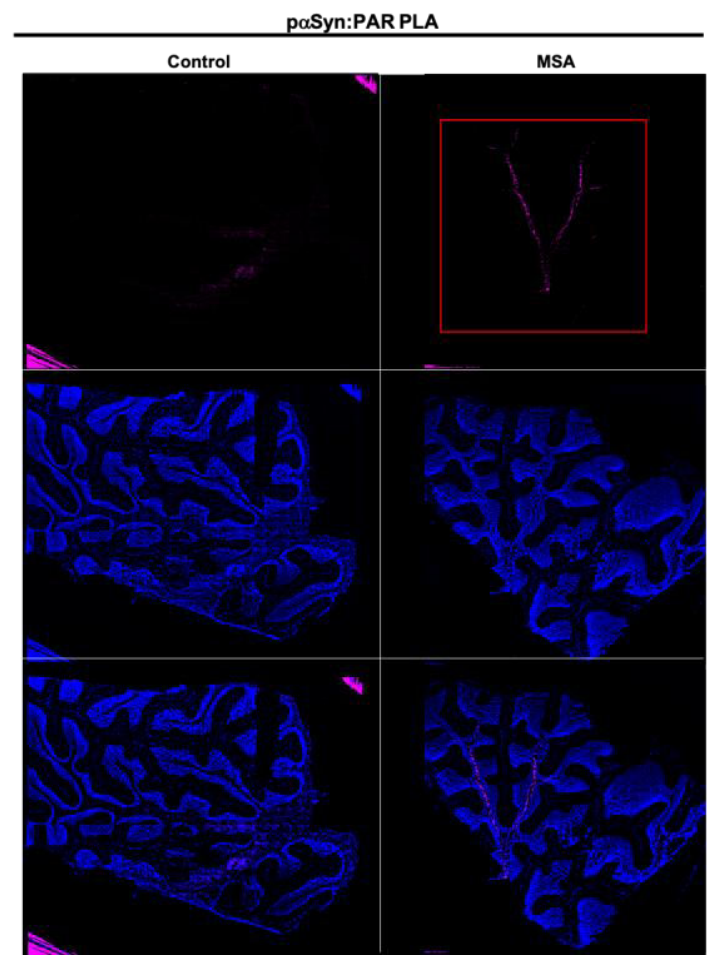

b

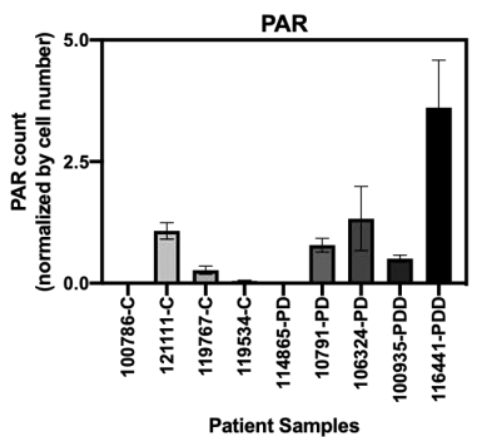

d

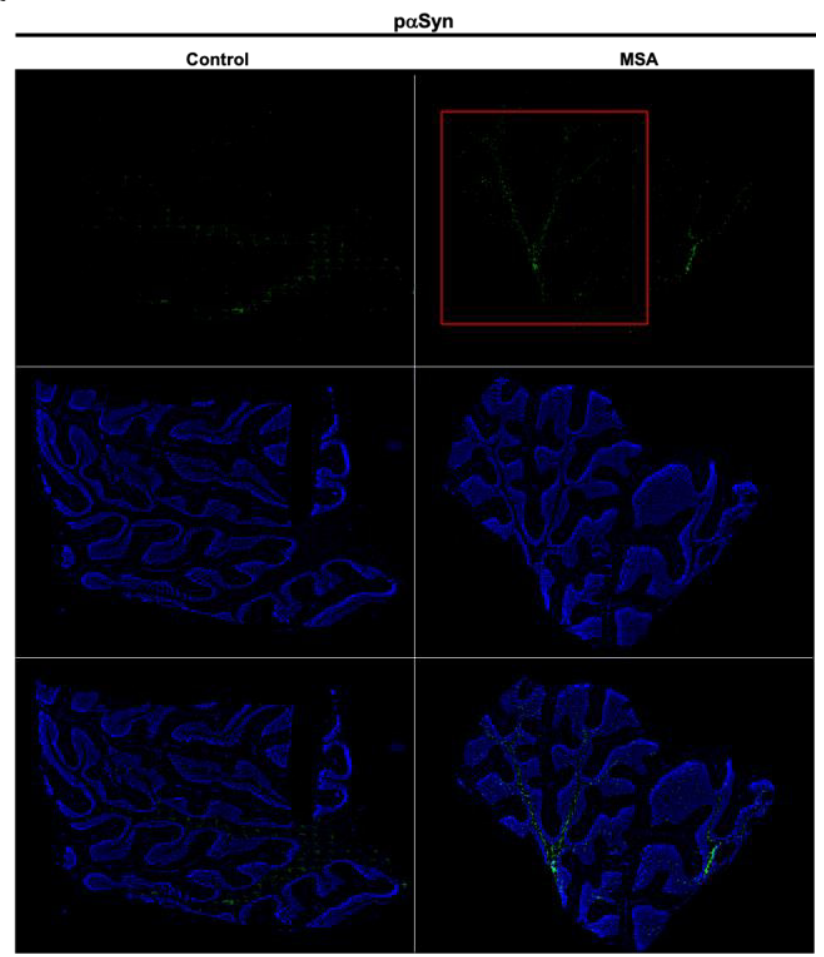

Extended Data Fig 3. Characterization of PAR and paSyn expression in post mortem brain sections. ( $a$ and $b$ ) Immunostain quantification of $p \alpha S y n$ and PAR expression for all human PD/PDD and non-PD post mortem brain samples used in this study. (c) PLA on cerebellum sections from control and MSA patients showing PLA (top panel), DAPI (middle panel), and merge (bottom panel) channel images. (d) Standard immunostain of adjacent cerebellum sections from control and MSA patients showing paSyn (top panel), DAPI (middle panel), and merged (bottom panel) channel images. Red boxes indicate PLA signal (c) and matching paSyn IF (d) in adjacent MSA tissue sections. Images were captured using Zeiss Axio Widefield (20x/0.8) microscope. 
a

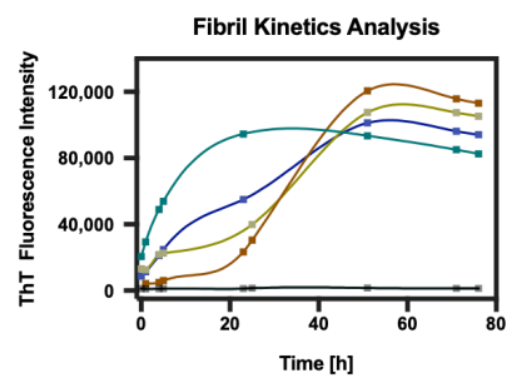

c

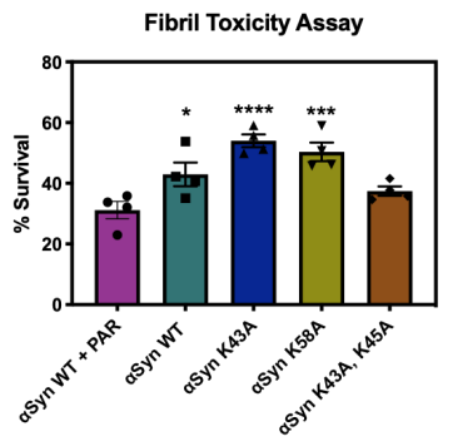

b

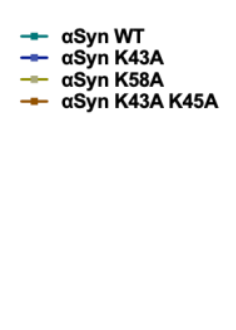

d
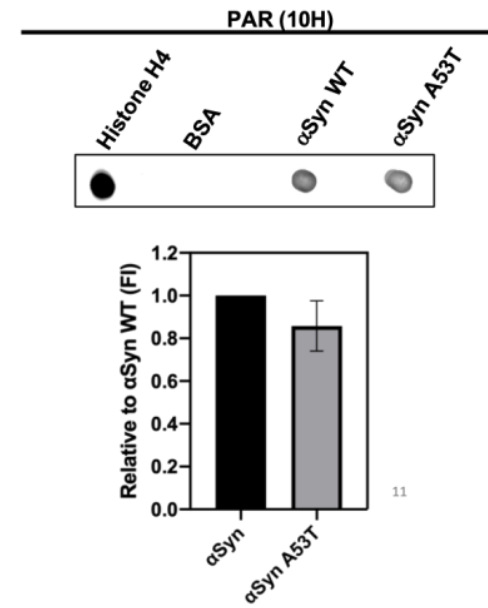

Extended Data Fig 4. Characterization of $\alpha$ Syn fibril and PAR binding. (a) ThT kinetic analysis and characterization of the three point mutants generated via site-directed mutagenesis against $\alpha$ Syn WT protein. (b) Fibril seeding variability of the three point mutants as determined by ThT kinetic analysis. (c) PFF cytotoxicity data on neuroblastoma cell line IMR-5. Cells were treated for 5 days with $750 \mathrm{nM}$ PFF. Bars represent means \pm SEM. Two-way ANOVA followed by Tukey's post hoc test $(\mathrm{n}=4)$. ${ }^{*} \mathrm{P}<0.03$, $* * * \mathrm{P}<0.0005, * * * * \mathrm{P}<0.0001$. (d) Representative PAR immunodot blot to assess PAR- $\alpha$ Syn A53T binding. Signal intensity was normalized to $\alpha$ Syn WT signal. Histone H4 and BSA were used as positive and negative controls for PAR binding respectively. 


\section{Supplementary Information}

\section{Supplementary Table 1. Antibody information}

\begin{tabular}{|c|c|c|c|c|}
\hline Antibody & Antigen & $\begin{array}{l}\text { Host } \\
\text { Species }\end{array}$ & Dilution & Source \\
\hline A11 & oligomers & Rabbit & $1: 10,000$ (DotBlot) & ThermoFisher \\
\hline Syn303 & $\begin{array}{l}\alpha \text { Syn } \quad \text { (target } \quad \text { N-terminus, } \\
\text { conformation specific) }\end{array}$ & Mouse & $1: 500(\mathrm{WB})$ & Biolegend \\
\hline$\gamma \mathrm{H} 2 \mathrm{AX}$ & $\gamma \mathrm{H} 2 \mathrm{AX}$ & Mouse & $1: 1000(\mathrm{WB})$ & MilliporeSigma \\
\hline Histone $3(\mathrm{H} 3)$ & Histone 3 & Rabbit & $1: 1000(\mathrm{WB})$ & CST \\
\hline $81 \mathrm{~A}$ & aSyn (Phosphorylation at Ser-129) & Mouse & $1: 1,000$ (IF; cells) & Abcam \\
\hline$\alpha \operatorname{Syn}(\mathrm{PS} 129)$ & $\alpha$ Syn (Phosphorylation at Ser-129) & Rabbit & 1:500 (IF, PLA) & Abcam \\
\hline $\operatorname{PAR}(10 \mathrm{H})$ & PAR & Mouse & $\begin{array}{l}\text { 1:500 (IF, PLA; cells), 1:1000 } \\
\text { (IF, PLA; tissue), 1:5,000 } \\
\text { (DotBlot) }\end{array}$ & Enzo \\
\hline Goat $F(a b)$ anti-Mouse IgG (H\&l) & Mouse IgG & Mouse & 1:100 (IF \& PLA; murine tissue) & Abcam \\
\hline$\alpha \operatorname{Syn}(\mathrm{PAN}-\alpha \operatorname{Syn})$ & $\alpha$ Syn (targets C-terminus, polyclonal) & Rabbit & 1:500 (PLA) & Invitrogen \\
\hline IRDye 800 Goat anti-Mouse & Mouse IgG & Mouse & 1:5,000 (PAR DotBlot) & $\begin{array}{l}\text { LI-COR } \\
\text { Biosciences }\end{array}$ \\
\hline $\begin{array}{l}\text { Goat anti-Mouse } \operatorname{IgG} \text { Alexa Fluor } \\
800\end{array}$ & Mouse IgG & Mouse & $1: 10,000(\mathrm{WB})$ & Invitrogen \\
\hline $\begin{array}{l}\text { Goat anti-Rabbit IgG Alexa Fluor } \\
680\end{array}$ & Rabbit IgG & Rabbit & 1:10,000 (WB, A11 DotBlot) & Invitrogen \\
\hline $\begin{array}{l}\text { Goat anti-Rabbit IgG Alexa Fluor } \\
568\end{array}$ & Rabbit IgG & Rabbit & $1: 400$ (IF) & Invitrogen \\
\hline $\begin{array}{l}\text { Goat anti-Mouse IgG Alexa Fluor } \\
489\end{array}$ & Mouse IgG & Mouse & $1: 400$ (IF) & Invitrogen \\
\hline PLA Probe Anti-Rabbit PLUS & Rabbit IgG & Rabbit & 1:5 (PLA) & MilliporeSigma \\
\hline PLA Probe Anti-Mouse MINUS & Mouse IgG & Mouse & 1:5 (PLA) & MilliporeSigma \\
\hline
\end{tabular}




\section{Supplementary Table 2. Animal Information}

\begin{tabular}{|llll|}
\hline Strain & Sex & Age & Group \\
M83 SCNA*A53T & M & 6 & M83 Tg young \\
M83 SCNA*A53T & M & 7 & M83 Tg young \\
M83 SCNA*A53T & M & 8 & M83 Tg young \\
M83 SCNA*A53T & M & 12 & M83 Tg aged \\
M83 SCNA*A53T & M & 15 & M83 Tg aged \\
M83 SCNA*A53T & M & 17 & M83 Tg aged \\
${ }^{1}$ B6C3F1/J & $M$ & 12 & B6C3F1/J aged \\
${ }^{1}$ B6C3F1/J & $M$ & 12 & B6C3F1/J aged \\
${ }^{1}$ B6C3F1/J & $M$ & 17 & B6C3F1/J aged \\
1non-Tg mice (littermate control) & & \\
\hline
\end{tabular}

\section{Supplementary Table 3. Patient Information}

\begin{tabular}{|c|c|c|c|c|}
\hline INDDID & Clinical Group & Age at Death & Sex & Region \\
\hline 100786 & Control & 61 & M & Striatum \\
\hline 119767 & Control & 83 & $\mathrm{M}$ & Striatum \\
\hline 119534 & Control & 72 & $\mathrm{~F}$ & Striatum \\
\hline 121111 & Control & 68 & M & Middle Frontal Gyrus \\
\hline 114865 & PD & 62 & M & Striatum \\
\hline 107091 & PD & 72 & $\mathrm{~F}$ & Striatum \\
\hline 100935 & PDD & 80 & M & Striatum \\
\hline 106324 & PD & N/A & N/A & Middle Frontal Gyrus \\
\hline 116441 & PDD & 82 & $\mathrm{M}$ & Middle Frontal Gyrus \\
\hline
\end{tabular}




\section{Supplementary Table 4. Microscopy Settings}

\begin{tabular}{|c|c|c|c|c|c|c|c|c|c|c|c|}
\hline $\begin{array}{l}\text { Confocal } \\
\text { Figure }\end{array}$ & Equipment & Objective lens & $\begin{array}{l}\text { Beam Splitter } \\
\text { Name }\end{array}$ & Beam Splitter Filter & $\begin{array}{l}\text { Acquisition } \\
\text { software }\end{array}$ & $\begin{array}{l}\text { Acquisition } \\
\text { Info. }\end{array}$ & $\begin{array}{l}\text { Bit } \\
\text { Depth }\end{array}$ & Gain & $\begin{array}{l}\text { Wavelength } \\
\text { End/Start }\end{array}$ & Illumination Channel P & ower \\
\hline $2 \mathrm{~A}$ & Zeiss LSM 710 & $\begin{array}{l}\text { 40x/1.1 W Korr } \\
\text { M26 }\end{array}$ & HT; MBS_InVis & $488 / 561$ & ZEISS, ZEN & Zeiss LSM & 8 Bit & $\begin{array}{l}848 \text { (DAPI); } 566 \\
\text { (Alexa Fluor } \\
488 \text { ) }\end{array}$ & $\begin{array}{l}417-484 ; 504- \\
572\end{array}$ & 5 (DAPI); 1 (Alexa Fluo & r 488) \\
\hline $2 \mathrm{C}$ & Zeiss LSM 711 & $\begin{array}{l}\text { 40x/1.1 W Korr } \\
\text { M27 }\end{array}$ & $\begin{array}{l}\text { HT; MBS_InVis; } \\
\text { FW1 }\end{array}$ & $488 / 561 / 633$ & ZEISS, ZEN & Zeiss LSM & $8 \mathrm{Bit}$ & $\begin{array}{l}728 \text { (DAPI); } \\
598 \text { (Alexa Fluor } \\
\text { 488); } 789 \text { (Alexa } \\
\text { Fluor 568) }\end{array}$ & $\begin{array}{l}417-484 ; 504- \\
572 ; 643-750\end{array}$ & $\begin{array}{l}7.8 \text { (DAPI); } 0.7 \text { (Alexa } \mathrm{F} \\
1.1 \text { (Alexa Fluor } 647 \text { ) }\end{array}$ & Fluor 488); \\
\hline $\begin{array}{l}\text { Widefield } \\
\text { Figure } \\
\end{array}$ & Equipment & Objective lens & Reflector & Filters & $\begin{array}{l}\text { Acquitision } \\
\text { software }\end{array}$ & $\begin{array}{l}\text { Acquisition } \\
\text { Info. }\end{array}$ & $\begin{array}{l}\text { Bit } \\
\text { Depth } \\
\end{array}$ & Excitation & Emission & Exposure & Camera \\
\hline 3B & Zeiss Axio Imager.M2 & $20 \mathrm{x} / 0.8 \mathrm{M} 27$ & 50 Cy $5 ; 49$ DAPI & $\begin{array}{l}625-655 ; 665-715 ; \\
335-383 ; 420-470\end{array}$ & ZEISS, ZEN & $\begin{array}{l}\text { Carl Zeiss } \\
\text { Image }\left({ }^{*} \text {.czi) }\right.\end{array}$ & $14 \mathrm{Bit}$ & $\begin{array}{l}625-655(\mathrm{Cy} 5) \\
335-383( \\
\text { DAPI) }\end{array}$ & $\begin{array}{l}665 \text { - } 715 \text { (Cy 5); } \\
420 \text { - } 470 \text { (DAPI) }\end{array}$ & $\begin{array}{l}2.8 \mathrm{~s} \mathrm{~ms}(\mathrm{Cy} 5) ; 150 \mathrm{~ms} \\
\text { (DAPI) }\end{array}$ & BW \\
\hline $3 \mathrm{C}$ & Zeiss Axio Imager.M2 & $20 \mathrm{x} / 0.8 \mathrm{M} 27$ & 50 Cy $5 ; 49$ DAPI & $\begin{array}{l}625-655 ; 665-715 \\
335-383 ; 420-470\end{array}$ & ZEISS, ZEN & $\begin{array}{l}\text { Carl Zeiss } \\
\text { Image (*.czi) }\end{array}$ & $14 \mathrm{Bit}$ & $\begin{array}{l}625-655(\text { Cy5); } \\
335-383( \\
\text { DAPI) }\end{array}$ & $\begin{array}{l}665-715 \text { (Cy 5); } \\
420-470 \text { (DAPI) }\end{array}$ & $\begin{array}{l}600 \mathrm{~ms}(\mathrm{Cy} 5) ; 190 \mathrm{~ms} \\
\text { (DAPI) }\end{array}$ & BW \\
\hline $3 \mathrm{E}$ & Zeiss Axio Imager.M2 & $20 \mathrm{x} / 0.8 \mathrm{M} 27$ & 50 Cy $5 ; 49$ DAPI & $\begin{array}{l}625-655 ; 665-715 ; \\
335-383 ; 420-470 \\
625-655 ; 665-715 ;\end{array}$ & ZEISS, ZEN & $\begin{array}{l}\text { Carl Zeiss } \\
\text { Image (*.czi) }\end{array}$ & $14 \mathrm{Bit}$ & $\begin{array}{l}625 \text { - } 655 \text { (Сy5); } \\
335 \text { - } 383( \\
\text { DAPI) } \\
625 \text { - } 655 \text { (Cy5); } \\
450 \text { - } 490 \text { (GFP); }\end{array}$ & $\begin{array}{l}665 \text { - } 715 \text { (Cy 5); } \\
420 \text { - } 470 \text { (DAPI) } \\
665 \text { - } 715 \text { (Cy 5); }\end{array}$ & $\begin{array}{l}600 \mathrm{~ms}(\mathrm{Cy} 5) ; 190 \mathrm{~ms} \\
\text { (DAPI) }\end{array}$ & BW \\
\hline $4 \mathrm{~A}$ & Zeiss Axio Imager.M2 & $20 \mathrm{x} / 0.8 \mathrm{M} 27$ & $\begin{array}{l}50 \text { Cy } 5 ; 38 \text { GFP; } \\
49 \text { DAPI }\end{array}$ & $\begin{array}{l}450-490 ; 500-550 \\
335-383 ; 420-470\end{array}$ & ZEISS, ZEN & $\begin{array}{l}\text { Carl Zeiss } \\
\text { Image (*.czi) }\end{array}$ & $14 \mathrm{Bit}$ & $\begin{array}{l}335-383( \\
\text { DAPI) }\end{array}$ & $\begin{array}{l}500 \text { - } 550 \text { (GFP); } \\
420 \text { - } 470 \text { (DAPI) }\end{array}$ & $\begin{array}{l}1.6 \mathrm{~ms} \text { (Cy 5); } 300 \mathrm{~ms} \\
\text { (GFP); } 190 \mathrm{~ms} \text { (DAPI) }\end{array}$ & BW \\
\hline $5 \mathrm{~A}$ & Zeiss Axio Imager.M2 & $20 \mathrm{x} / 0.8 \mathrm{M} 28$ & 50 Cy $5 ; 49$ DAPI & $\begin{array}{l}625-655 ; 665-715 \\
335-383 ; 420-470\end{array}$ & ZEISS, ZEN & $\begin{array}{l}\text { Carl Zeiss } \\
\text { Image (*.czi) }\end{array}$ & $14 \mathrm{Bit}$ & $\begin{array}{l}625-655 \text { (Cy5); } \\
335-383( \\
\text { DAPI) }\end{array}$ & $\begin{array}{l}665 \text { - } 715 \text { (Cy 5); } \\
420 \text { - } 470 \text { (DAPI) }\end{array}$ & $\begin{array}{l}1.6 \mathrm{~ms}(\mathrm{Cy} 5) ; 150 \mathrm{~ms} \\
\text { (DAPI) }\end{array}$ & BW \\
\hline S1B & Zeiss Axio Observer.Z1 & 40x/1.4 Oil & 38 GFP; 43 DsRed & $\begin{array}{l}450-490 ; 538-562 \\
500-550 ; 570-640\end{array}$ & ZEISS, ZEN & $\begin{array}{l}\text { Carl Zeiss } \\
\text { Image (*.czi) }\end{array}$ & $12 \mathrm{Bit}$ & $\begin{array}{l}450 \text { - } 490 \text { (GFP); } \\
538 \text { - } 562 \text { (Ds } \\
\text { Red) }\end{array}$ & $\begin{array}{l}500 \text { - } 550 \text { (GFP); } \\
570 \text { - } 640 \text { (Ds Red) }\end{array}$ & $\begin{array}{l}2 \mathrm{~s} \text { (GFP); } 690.2 \mathrm{~ms} \\
\text { (DsRed) }\end{array}$ & $\begin{array}{l}\text { Monochr } \\
\text { ome }\end{array}$ \\
\hline
\end{tabular}

